\title{
Prison Sentence TRendS by AREA TYPe: 1985-2001
}

Pamela E. Oliver (June 2012)

NOTE: This is a working paper based on my ongoing analysis of prison admissions from the National Corrections Reporting Program that is subject to further refinement and correction.

Abstract:

National-level trends in racial patterns of incarceration hide the fact that different trends were happening in different kinds of places. Overall, the national Black prison admission rate leveled off after 1995 while the White rate continued to rise. Detailed investigation of types of places reveals that the national trend for Blacks hides a steep decline in Black prison admissions in a few large metropolitan areas coupled with a continued rise in other places, especially those where Blacks were a smaller percentage of the population. White prison admission rates were consistently low and relatively stable in the large metropolitan areas. The growth in White prison admission was concentrated in rural areas and smaller cities that were overwhelmingly White. These trends have not been noticed in the prior literature and require further research.

In most popular and academic accounts, crime and imprisonment are associated with urban Blacks or other minorities, and it is the big cities with lots of Blacks that are viewed as both the core of the imprisonment problem and the core of the Black/White disparity. There is a core of truth in this impression: a relatively small number of large metro areas accounted for a very large share of the Black population and Black incarceration. These large metro areas also had the highest violent crime rates. But when we dig down and carefully disaggregate imprisonment rates by race and place, we can see evidence of the ethnic-racial dynamics of social control. In particular, we show that White-dominated areas accounted disproportionately for the steep growth in White imprisonment. The different dynamics in the Black metropolises and the White areas account for the divergent patterns of Black and White incarceration after 1995. In this analysis we focus on the period 1988-2001 because it permits us to include Miami and other Florida cities, which had very high imprisonment rates in the late 1980s and for which we do not have data for before 1988.

\section{LARGE METRO AREAS}

As can be seen in Table 1, seventeen metropolitan areas combined accounted for half of all new Black prison admissions in the NCRP sample between 1988 and 2001. ${ }^{1}$ Just four areas (Los Angeles, New York, Chicago, and San Francisco - Oakland) accounted for $25 \%$ of Black prison admissions. If we look at new sentences (excluding revocations) we swap Miami for San Francisco and account for $22 \%$. National trends in Black prison admissions 
were disproportionately shaped by these few areas. As the table indicates, these 17 areas differed markedly in their over- or under-representation in prison admissions averaged across 1988-2001. Taken as a group, their prison admissions across all years was proportionate to their combined population. Revocations were exceptionally high in Los Angeles and San Fancisco/Oakland (as for all of California), with other areas being at or below representation. Looking at new sentences, New York, Detroit, Philadelphia, Atlanta and Virginia Beach were underrepresented relative to population, while all the others were overrepresented. Tampa was an especially large source of Black prison admissions despite having a relatively small Black population.

The comparable figures for Whites for these same seventeen areas are shown in Table 2. All the areas taken together account for only $27 \%$ of White prison admissions. Again Los Angeles and San Francisco have a disproportionate share of revocations, but Atlanta is also above average for White revocations. The Florida and Texas cities along with Los Angeles and Atlanta have higher White prison admission and sentence rates than average; Baltimore, Virginia Beach and Cleveland are just about average, while New York, New Jersey, Philadelphia, Chicago, and Detroit have lower rates than average.

Although our focus is on Blacks and Whites, it is instructive to see comparable information for Hispanics, as shown in Table 3. These 17 areas account for over half of the Hispanic population and prison admissions, with Los Angeles alone accounting for $25 \%$ of Hispanic prison admissions and New York another $13 \%$. Although New York is below average for White and Black imprisonment, it is way above average for Hispanic imprisonment. Philadelphia is also overrepresented but its small numbers make it unimportant for Hispanic trends. Notably, the Florida and Texas cities are far below national representation in their Hispanic prison admissions while they are way above average for Blacks and Whites. Many of the cities that are major sources of Black imprisonment are essentially irrelevant for Hispanics.

So far we see two important patterns. First, the big metro areas are more important elements in the national patterns for Blacks and Hispanics than for Whites. Second, these big metro areas varied markedly in their racial imprisonment patterns. Los Angeles was above average for all races, even for new sentences and especially for revocations. All the other areas were above average for some racial group and below average for another.

\section{COMPARING TRENDS FOR LARGE METRO AREAS VERSUS ELSEWHERE}




\section{BLACKS}

These large Black metropolitan population centers had different racial patterns from the rest of the country. As the series began in 1988, well over half of Black prison admissions came from these 17 areas, as Figure 1 shows. However, beginning in 1990 Black prison admissions in the 17 large metro areas declined and then leveled off, while Black prison admissions elsewhere rose steeply through 1995 before leveling off. The trend for Black sentences in (Figure 2) is even more striking. The 17 large areas accounted for $60 \%$ of all new sentences in 1988-1990, but then sentences in these areas dropped through 1994, showed a bump in 1995, and then fell again. In contrast, sentences in other areas stayed level through the late 1990s and then rose steeply. By the end of the series, these 17 areas account for only $45 \%$ of Black prison sentences.

The trend for Black new sentences in the 17 big areas is a composite of separate trends that can be seen in Figure 3. There were steep rises in Black imprisonment between 1984 and 1990 in every area for which we have data, although places varied in the timing of the upturn and its extent. The decline after 1990 is driven primarily by a steep drop in Black prison sentences in New York and the Florida and Texas metro areas. The 1995 bump (which followed the 1994 crime bill that provided states with incentives to pass three strikes bills and more money for prisons) is especially strong in Texas (which also had a major administrative change that year that somewhat artificially generated a large number of prison admission records) ${ }^{2}$ but also shows up in Northern New Jersey and Baltimore and slightly in Chicago and Los Angeles. There is no bump at all in New York, Atlanta, Detroit, Cleveland or Philadelphia. The decline in the late 1990s is due primarily to the continuing decline in New York and a decline in Los Angeles, Cleveland and Baltimore that offset the rise in Atlanta and the flat trend in the other metro areas. The post-2000 bump for most areas shows up strongly in the 17 metro areas only in Chicago, Cleveland (where it is largely an artifact of coding rules) ${ }^{3}$, a bit in Detroit, and the continuing rise in Atlanta, Tampa and Jacksonville..

The prison sentence trend is also a composite of patterns that vary by offense type. The large metro areas accounted for over $60 \%$ of the drug sentences in 1988 but their share fell to close to $50 \%$ by 1993 after drug sentences declined in the large metro areas (Figure 4). From the mid-1990s on, Black drug sentences were relatively stable in both types of places. The large metro areas similarly initially accounted for about $60 \%$ of robbery and burglary sentences but these fell steeply in the large metro areas after 1990 while remaining virtually constant in other areas (Figure 5) so that most Black robbery/burglary sentences were outside the large metro 
areas after 1997. Black violence sentences declined somewhat after 1990 in large metro areas while continuing to rise elsewhere, with the balance shifting in 1991 (Figure 6). Black theft sentences were always less common in the large metro areas and exhibited relatively similar patterns overtime that left the balance the same (Figure 7). Finally, the grab bag of "other" offenses increased steadily outside the large metro areas but not inside them, declining at the end of the 1990s within the big metro areas (Figure 8). Summing up, the growth in Black prison sentences outside the large metro areas after the early 1990s was primarily in sentences for violence and other offenses. The decline in prison sentences in the large metro areas was steepest for robbery/burglary and was timed differently for different offenses.

\section{WHITES}

The large metro areas were also a declining source of imprisonment for Whites. White prison admissions rose much more modestly in these 17 areas than in the rest of the country, as Figure 9 shows for total admissions and Figure 10 shows for new sentences. Figure 11 shows the 17 metro trends for Whites, organized on the same scheme as for Blacks. What stands out most in the White trends is the greater importance of metro areas in California, Texas and Florida and the markedly lower importance of New York and Chicago relative to the Black trends. Only the Florida and Texas metro areas and Atlanta showed a decrease after 1990; the 1995 bump was, as expected, primarily concentrated in Texas. Only Cleveland shows the post-2000 increase that is apparent in many other areas. Apart from these patterns, the metro areas were relatively stable in their White prison sentences.

As for Blacks, disaggregating by offense reveals patterns worthy of further exploration. Drug sentences show a steady decline in the importance of the large metro areas especially after 1995 when White drug sentence rates rise steeply elsewhere but not in the metro areas (Figure 12). White sentences for violence (Figure 13) other offenses (Figure 14) rose after 1995 outside the large metro areas but not in them. White sentences for robbery/burglary (Figure 15) and theft (Figure 16) were largely stable for other areas but declining in the large metro areas.

Table 4 provides a verbal summary of these patterns. Outside the large metro areas, the Black and White trends were similar within offense groups, except that White drug sentences increased after 1995 and Black drug sentences did not. But these areas were a much more important part of the total trend for Whites than Blacks. Inside the large metro areas the picture is a little more complex as Black sentences showed a steep increase for 
drugs, violence and robbery/burglary through 1990 followed by a decline while the White rates fluctuated less; Blacks show a decline for other offenses after 1995 while Whites do not; both races showed declines in theft sentences. We saw earlier that most of the post-1990 decline for Blacks was concentrated in the big metro areas of Texas, Florida and New York. Overall there are clues that the different national patterns by race are heavily influenced by the compositional affects of who lives where. But we also see that not only were the big metro areas disproportionately the sites of Black prison sentences in the late 1980s and early 1990s before declining, these same areas were not disproportionately the sites of White prison sentences. Further it appears that virtually all of the impact of the 1994 omnibus crime bill on imprisonment happened outside the large metro areas.

In short, very little of the "action" in the rising White imprisonment rates is happening in the big metropolitan areas (except Los Angeles). Whatever is going on with Whites is happening elsewhere. We will seek to track that down in the next section.

Finally we may briefly consider the Hispanic trends. As Figure 17 for total admissions and Figure 18 for sentences indicate, these 17 metro areas account for well over half of Hispanic prison admissions. The metro areas show a steep rise through 1995 and then a decline. The Although New York's Hispanic sentences drop after 1990 (as for Blacks), this is dwarfed by steep growth in Los Angeles and Dallas. Sentences in Los Angeles and Dallas start to fall after 1995.

\section{Prison Sentences and AREA Types: Racial deMographics AND RURAL AREAS}

Revocation rates are primarily state-level phenomena and California accounts for over $30 \%$ of all revocations. There is more local variation within states for new sentences. Just as with the largest metro areas, smaller metro areas each have their own distinctive trends by race and offense over time. But by grouping them we can identify some of the important general patterns across groups. Because of a problem of changing county codes across time, North Carolina has to be dropped from sub-state analyses although its state-level NCRP data are good. We create five groups of areas:

1. The 17 large metro areas that each accounted for at least $1 \%$ of Black prison sentences

2. The 43 other metro areas that $15 \%$ or more Black ${ }^{4}$

3. The 160 other metro areas that are less than $15 \%$ Black

4. The non-metro balance in 19 states where the non-metro balance was less than $5 \%$ Black. $^{5}$ 
5. The non-metro balance in 8 states where the non-metro balances was $8 \%$ or more Black.

The percent Black in the non-metro areas is quite skewed: Mississippi 36\%, South Carolina 31\%, Alabama 24\%, Georgia 24\%, Maryland 14\%, Virginia 13\%, Florida 11\%, Texas $8 \%$, then $4.5 \%$ on down. Texas has relatively high imprisonment rates and has been grouped with the high percent Black states; if it were included with the low percent Black states, the rates below for group 5 would be lower and for group 4 would be higher. Nine of the 17 large metro areas were more than 15\% Black. The ones that were not were Miami (just under 15\%), Dallas (13\%), Orlando(11\%), Northern New Jersey (11\%), San Francisco (10\%), Los Angeles (8\%), and Tampa (8\%).

Whites and Blacks differ markedly in their distribution across these area types within the NCRP area sample. Fully $51 \%$ of Blacks covered by the NCRP sample of metro areas lived in the 17 large metro areas while only about $2 \%$ lived in the rural areas that are less than $5 \%$ Black. About $20 \%$ lived in metro areas that were less than $15 \%$ Black and about $16 \%$ in metro areas that were more than $15 \%$ Black. About $10 \%$ lived in the rural areas that were at least $8 \%$ Black. The White population had significant numbers in all area types. The plurality, just about 39\%, lived in other metro areas that were less than $15 \%$ Black, about $32 \%$ lived in the 17 large metro areas, about $16 \%$ lived in rural areas that were less than $5 \%$ Black, about $7 \%$ in metro areas that were $15 \%$ or more Black and about $6 \%$ in rural areas that were $8 \%$ or more Black.

Figure 19 shows that the proportion of all Black prison admissions coming from the large metro areas declined over time while the proportion coming from other metro areas that were less than $15 \%$ Black rose; the proportions coming from other area types changed only slightly across time. The picture is different for Whites, as Figure 20 shows. Both metro and rural areas with low percent Black (groups 3 and 4) grew in importance relative to large metro areas; the proportion in the high percent Black areas is growing too, but it is of negligible importance for the White rates. For Hispanics, we see a decline in the large metro areas balanced by a rise in the other metro areas that were less than 15\% Black Figure 21. The discrepant rural pattern for Whites gets lost when all the races are combined, as in Figure 22 because the racial disparities are so large.

The rates in each type of area can be seen in Figure 23 for Black prison sentences and Figure 24 for White prison sentences. For Blacks, the most important distinction appears to be percent Black: the urban areas that are more than 15\% Black (group 2) have the lowest Black rates, followed by the rural areas that are more than $8 \%$ Black (group 5). Metro areas than were less than 15\% Black had the highest sentence rates after 1992 and rural 
areas that were less than 5\% Black the second highest rate after 1994 . As we have previously noted, the large metro areas showed declines from the highest to moderate rates. For Whites, the most important distinction in new sentences appears to be rural/urban: by the end of the series, the two types of rural areas had higher sentence rates than the different types of metro areas. Rural areas that were $8 \%$ or more Black (group 5) were consistently high, while rural areas that were $5 \%$ or less Black (group 4) started with the lowest prison sentence rates and ended second highest by the end of the series. For Whites, there was also substantial growth in prison sentences in other metro areas (both group 2 and group 3) after 1995. The largest metro areas had low White prison sentence rates after 1992. As the previous set of pictures showed, the growth in group 2 (metro areas that were at least $15 \%$ Black) was of negligible importance in the national trend.

As the previous set of figures contrasting the large metro areas with other areas suggested, these patterns vary somewhat across offense groups. ${ }^{6}$ The previous section contrasted the large metro areas with all others; this discussion focuses on variations within the "other" areas. Table 5 presents a qualitative summary of graphs that are available in the on-line appendix. The patterns for Black sentence rates vary only slightly from the main pattern that rates are low where the percent Black is high, high in other metro areas with a low percent Black, and rising in rural areas with a low percent Black. Theft shows more oscillation than trend in rural areas and was declining in metro areas. Trends varied by offense in the low percent Black metro areas, declining for theft and robbery/burglary, stable for violence and drug offenses, and rising for other offenses.

Trends in White prison sentence rates show some more complex interactions between area type and offense group. Group 5 (rural areas that were at least $8 \%$ Black) had especially high White rates throughout the series for all offenses except drugs where there was a curvilinearity and showed growth after 1995 for all offenses except theft. Group 4 (rural areas that were less than 5\% Black) showed steep growth for violence and other offenses, rising from similar to metro areas in 1988 to substantially higher than metro areas by the end of the1990s; drug offense sentence rates also grew steeply for group 4 from lower than metro to comparable to metro rates. However robbery/burglary was low and stable in group 4 and theft stay low although it was rising. Group 3 (metro areas with less than 15\% Black) exhibited similar trends to group 4 (rural White) with comparable rates for drug, robbery/burglary and theft and somewhat lower rates than group 4 for violence and other offenses. Group 2 (metro areas at least 15\% Black) generally had high stable theft sentence rates, declining moderate 
robbery burglary sentence rates, low but rising violence and other sentence rates and a curvilinear trend that ended low for drug sentences.

Theft stands out from other offenses as having a percent Black effect for Whites: White theft sentence rates were highest in rural areas that were at least $8 \%$ Black (group 5) and second highest in other metro areas that were at least 15\% Black (group 2). (Recall that for Blacks, sentence rates were lowest in these two groups.) It is not clear how to explain this pattern. Figure 25 shows that the theft crime rate (which is not race specific) was highest after 1994 in group 2 (metro areas that are 15\%+ Black) but was lower than any metro group in group 5 (rural areas at least $8 \%$ Black). However, the prison sentence to crime ratio for theft (Figure 26)was substantially higher in group 5 than in other areas and is second highest in group 2 . The prison/crime ratio for theft grew for group 4 (rural areas less than 5\% Black) after 1994 and reached the group 2 level by 1996. This is more evidence of "action" in rural areas for the 1990s imprisonment increases.

To summarize, the growth in White imprisonment in the 1990s was happening mostly in rural areas and smaller metro areas that were less than $15 \%$ Black and was happening primarily in violence, drug, and other offenses (primarily drunk driving), not in the property offenses. Black sentence rates were consistently rising in rural areas with few Blacks (where their numbers were too small to impact national trends) and for "other" offenses in metro areas with few Blacks, but were otherwise stable or declining. In large metro areas, prison sentence rates first rose steeply and then declined for Blacks while they stayed relatively low for Whites. But these areas had a much bigger impact on the national patterns for Blacks than for Whites. Outside these large metro areas, in areas with higher percents Black where more Blacks live, Black imprisonment rates stabilized at a lower level for drug crimes, were declining for property crimes, and were relatively steady for violence and other offenses. In the places where Blacks were a smaller proportion of the population, Black prison sentence rates stayed high and were rising for other offenses and, in nonmetro areas, for drug offenses, but these areas were a small part of the total. By contrast, white prison sentence rates rose steeply after 1995 outside the large metro areas and especially steeply in the nonmetro areas. This rise was most steep for sentences for drug and "other" offenses but the trend was also upward for violence; theft and robbery/burglary showed less trending.

DOES CRIME EXPLAIN THE RURAL WHITE TRENDS? 
Finding the rise in White prison sentences in rural areas was unexpected and the data being analyzed are not well suited to identifying exactly what causal factors are at work. Crime trends are not race-specific but it is instructive to compare crime rates by the area types for violence in (Figure 27), for robbery/burglary in (Figure 28), and for theft in (Figure 25). Most of the rise is due to increases in drug and other offenses (especially drunk driving), so it is not really surprising that there is no evidence of a crime rise after 1995 in rural areas. The Whitedominated rural areas (group 4) continued to have the lowest crime rates of any area type and the crime rates in the rural areas with significant Black population (group 5) were lower than for all metro area types for theft and robbery/burglary and for violence were comparable to the low percent Black metro areas (group 3). The prison/crime ratio for violence was especially high and rising steeply in the White dominated rural areas (group 4, see Figure 29). For robbery/burglary (Figure 30), the prison/crime ratio was highest in the southern rural areas with high percent Black; it was rising for all groups but fastest in the White-dominated rural areas (group 4). There is a similar pattern for theft (Figure 31). This looks like the White imprisonment rise in rural areas was due more to escalated social control than a response to an escalated crime problem. The rising rates of White imprisonment for "other" offenses, which are largely drunk driving, is known to be tied to changes in the penalties for drunk driving, not to a rise in offending. There is widespread popular discussion of a rising problem with illegal drugs in White rural areas. $^{7}$ The post-1995 rise in White drug sentences occurs across all area types except the large metro areas. In future chapters we will be looking for additional clues about what was happening.

\section{CONSISTENCY CHECKS}

There are state-level effects on imprisonment practices and states vary in their mixture of urban and rural areas as well as in their racial admixture. I performed a variety of checks to see whether the observed trend in the nonmetro areas was general or an artifact. The trend of rising White non-metro imprisonment rates relative to the metro areas replicates within most states. ${ }^{8}$ This can be displayed visually by calculating the ratio of the imprisonment rate in a state's nonmetro areas to the rate in its metro areas; we take the logarithm of this ratio to improve its dispersion. A scatterplot using state initials as markers for this ratio for each state by year shows the trend. For Blacks (Figure 32), this ratio stays dispersed: it is greater than 1 (i.e. the log is greater than zero) for many states, and less than 1 for many others. Similarly, at the beginning of the 1980s, there are many states on both sides of the line for White rates (Figure 33). But as time passes, more and more states move from below the 
line to above it, showing that the steep rise in nonmetro areas was happening within states, not just between states.

I also examined the area types within states. The average White new sentence rate 1995-2001 was highest in the nonmetro balance for 15 of the 19 states where the nonmetro balance averaged less than 5\% Black and 5 of the 8 states where the nonmetro balance was $8 \%$ or more Black. Among the discrepant states with small Black rural populations, the metro and nonmetro rates were very close for Wisconsin; the nonmetro rate was close to the metro rate for some metro types and higher than others for Michigan; and was consistently lower in nonmetro than metro areas for Oklahoma and lowa. In the high percent Black rural areas, the nonmetro rate was higher than some metro types and lower than others for Texas (where rates were highest in the big metro areas and the metro areas that were more than 15\% Black) Georgia, and Alabama (where the highest rates were in metro areas that were less than $15 \%$ Black).

Finally, I looked at the within-state time trends. White prison sentences rose steeply after 1995 in the rural balance in almost all states. The only states in the NCRP with no evidence of a consistent rural balance rise after 1995 were Maryland and Wisconsin (which showed little rise across the series), California (which rose steeply before 1995 but damped out after), and Ohio (which declined after 1995 until 1999, but this may be a data problem). States where the post-1995 rise was moderate were New York, West Virginia, Alabama, Nevada and lowa. The other 17 states all exhibited steep rises in White prison sentence rates in the rural balance after 1995; some were also rising before 1995 and others were not.

\section{CONTINUOUS RELATIONS}

These patterns can be seen as continuous rather than typological effects. Predictor variables are the log of the average Black population, the Black population percentage, the Hispanic population percentage, and whether the area is a metro area or the non-metro balance of a state. Table 6 shows the regression for the average prison admission rates across all years. For Whites the most consistent significant predictor of the average imprisonment rate is percent Hispanic: areas with a higher percentage of Hispanics (especially the states of the Southwest including California, Texas, Nevada and Arizona but also Florida) have high White incarceration rates, but not high Black incarceration rates; percent Hispanic is thus negatively related to the Black/White disparity ratio. The only 
other significant predictor for Whites is that White prison sentence rates for property offenses (robbery/burglary and theft) are higher where the percent Black is higher. For Blacks, the consistent predictor of imprisonment rates is the negative effect of percent Black (for everything except theft sentences); rural areas generally have lower Black imprisonment rates for drug, violence and robbery/burglary offenses, and the size of the Black population (with percent Black controlled) has a negative relation to the average sentence rates for violence, theft and other. Black/White disparities were lower not only where there are more Hispanics, but where there are more Blacks (both in raw numbers and as a percentage of the population) and in rural areas.

Table 7 shows the regression for the change in rate between the 1988-1992 average and the 1998-2001 average. The rising White trend for rural areas can be seen in the positive coefficient on non-metro for new sentences overall and drug, violence and robbery/burglary sentences. Percent Hispanic again predicts the rise in White imprisonment for all offense categories except theft. The size of the Black population has a consistent negative effect on the change in White sentences, as we saw in the graphs where White imprisonment did not rise in the large metropolitan areas with large Black populations. However, controlling for the sheer size of the Black population, White imprisonment did rise more in smaller areas in which Blacks were a larger percentage of the population. Recall that graphs showed Black imprisonment declining in the large metropolitan areas and stabilizing in areas with significant Black population. This can be seen in the negative coefficients on Black population for drug and robbery/burglary sentences, and new sentences overall. There is a significant negative effect of percent Black for other offenses and revocations as well. The change in Black drug and other sentences was negatively related to the percent Hispanic. The coefficients for non-metro are generally positive as they are for Whites, indicating that Black rates declined less in rural areas, but the coefficient is significant only for sentences for robbery/burglary, which declined very steeply in metropolitan areas. As with the average rate, the change in the disparity was negatively related to the percent Hispanic due to the positive correlation for Whites and the negative correlation for Blacks. Otherwise there were only scattered significant effects on the change in the disparity ratio most notably the opposite signs on Black population and percent Black for violence sentences.

\section{TYING THESE RESULTS TO PREVIOUS RESEARCH}


I was surprised by the prison sentence trends for Whites and went looking to see if there is any literature on it. I could find nothing at all about imprisonment trends or social control trends among Whites outside major metropolitan areas. Most of the available literature seems wholly silent on even acknowledging, much less explaining, White imprisonment trends anywhere or rural imprisonment trends for any race. Official reports by the National Drug Intelligence Center and the National Alliance of Gang Investigators describe and categorize drug dealers almost exclusively in racial/ethnic terms with almost no mention of White non-immigrant drug dealers (National Alliance of Gang Investigators Associations 2006; National Drug Intelligence Center 2002; 2010).

There is somewhat more to consider regarding rural crime, although not much of it seems helpful for explaining the imprisonment patterns, since (as shown above) the rise in imprisonment was due to a rise in the prison/crime ratio, not a rise in crime. Weisheit and Wells (1996) complain about the urban bias in criminology and the failure to account for rural factors in crime. Fischer (1980) develops a theoretical argument that crime like other phenomena diffuses from urban to rural areas and illustrates this argument with data on the diffusion of crime waves 1955-1975 in California, where crime first peaked in Los Angeles and San Francisco and later in rural areas. These very general theoretical ideas might have some relevance to the spread of the drug trade outside major metropolitan areas. Bachman (1992) summarized crime victimization data and compared central cities, other metro areas and nonmetro areas, finding that crime was generally going down in all area types and that victimization risk was generally lower in rural areas although for some crime types it is comparable in rural and metro areas. Bachman cited a 1991 Senate report on rural crime which said that rural areas were suffering "a plague of violent crime, drug trafficking and drug abuse" but criticized that report because it used state-level comparison of "rural" states versus "urban" states and also used percentage changes.

More recent research has explored variations in crime rates among rural areas and paid attention to the issue of rural crime. Martin (1995) finds some evidence for increased rural crime along Interstate routes. In an investigation of 1995 crime rates from non-metropolitan counties, Rephann (1999) begins with the fact that crime was falling in metro areas in the 1990s but rising in rural areas even as it was still lower than for metro areas. Looking at arrests, she shows that some offenses are higher in rural areas, including offenses against families and children, fraud, manslaughter, and driving under the influence; by the end of the 1990s this expanded to include forgery, marijuana sale and possession, synthetic drugs sale and possession, burglary, arson, embezzlement. She 
discusses the ways in which "development" can increase crime, showing that tourism and the closeness of urban areas affect crime, while the presence of prisons and military bases affect arrests but not crime. Tunnell (2006) stresses the ways in which farm crises have increased disorganization in rural areas. Shihadeh and Barranco (2010) look at the relation between the rise in Latinos in rural labor markets and White violence as border enforcement which increased the number of low-skilled Latinos staying in the US, finding that only White violence is affected in rural areas, not Black.

Baker (2008) provides analysis of recent rural crime rates, using social disorganization theory specifically applied to rural areas. Berthelot, Blanchard and Brown (2008) tests whether female arrest rates for violence are tied to Scotch-Irish immigration patterns in the South, restricting their sample to Southern counties with total population in 2000 less than 20,000 finding contrary to their hypothesis that the White female homicide rate is negatively related to percent Southern and percent Scots-Irish and percent poor Brock and Walker (2005) used newspapers to compile records of crimes in four rural communities, one near Kansas City, one near Denver, and two in remote parts of states; the hypothesis was that rural areas near urban areas would show more influence of drug crimes, but this was found for only one of the "near urban" areas and not the other. Instead, the main conclusion is that there is a great deal of variability across time and between places in rural areas. Fitzgerald, Kalof and Dietz (2009) analyze non-metropolitan counties across time and argue that slaughterhouses produce a unique (if small) influence on certain crime rates, especially for rapes and assaults at the when slaughterhouse employment is at its maximum. Wells (2008) examine the crime victimization of Native Americans, who are usually ignored or lumped as "other" in most studies.

None of these studies of variations in crime rates across places and offenses addresses the social controls that seem to be present in the growing ratio of prison sentences to crimes in nonmetro areas. The data in this project are not appropriate for addressing any of the specific differences in rural areas.

At this point, we are left with a puzzle we cannot explain. 


\section{REFERENCES}

Bachman, Ronet. 1992. "Crime in Nonmetropolitan America: A National Accounting of Trends, Incidence Rates, and Idiosyncratic Vulnerabilities." Rural Sociology 57(4):546-60.

Baker, Ryan. 2008. "The Effects of Rural Disorganization on Crime: Investigating Official Crime Data." Conference Papers -- American Society of Criminology:1.

Berthelot, Emily R., Troy C. Blanchard, and Timothy C. Brown. 2008. "SCOTS-IRISH WOMEN AND THE SOUTHERN CULTURE OF VIOLENCE: THE INFLUENCE OF SCOTS-IRISH FEMALES ON HIGH RATES OF SOUTHERN VIOLENCE." Southern Rural Sociology 23(2):157-70.

Brock, Deon, and Darin Walker. 2005. "RURAL POLICING AND THE DRUG PROBLEM: AN EXAMINATION OF THE INFLUENCE OF MAJOR METROPOLITAN AREAS ON DRUG OFFENDING IN SURROUNDING RURAL COMMUNITIES." Police Journal 78(2 June):129-46.

Fischer, Claude S. 1980. "The Spread of Violent Crime from City to Countryside, 1955 to 1975." Rural Sociology 45(3):416-34.

Fitzgerald, Amy J., Linda Kalof, and Thomas Dietz. 2009. "Slaughterhouses and Increased Crime Rates." Organization \& Environment 22(2):158-84.

Martin, Douglas E. 1995. "CRIME ALONG RURAL INTERSTATE HIGHWAYS." Free Inquiry in Creative Sociology 23(2):105-08.

National Alliance of Gang Investigators Associations. 2006. "2005 NATIONAL GANG THREAT ASSESSMENT." Trends in Organized Crime 10(1):46-48.

National Drug Intelligence Center. 2002. "Drug trafficking in New Jersey: Prepared for the State Commission of Investigation." Trends in Organized Crime 7(3):58-65.

—. 2010. "National Drug Threat Assessment 2010: Drug Trafficking Organizations." U.S. Department of Justice.

Rephann, Terance J. 1999. "Links between rural development and crime." Papers in Regional Science 78(4):365.

Shihadeh, Edward S., and Raymond E. Barranco. 2010. "Latino Employment and Non-Latino Homicide in Rural Areas: The Implications of U.S. Immigration Policy." Deviant Behavior 31(5):411-39.

Tunnell, Kenneth D. 2006. "Socially disorganized rural communities." Crime, Media, Culture 2(3):332-37.

Weisheit, Ralph A., and L. Edward Wells. 1996. "Rural crime and justice: Implications for theory and research." Crime \& Delinquency 42(3):379-97.

Wells, Edward. 2008. "Violent Victimization of Native Americans: Trends and Patterns." Conference Papers -- American Society of Criminology:1. 


\section{List of Tables}


TABLE 1. PROPORTION OF BLACK POPULATION AND PRISON ADMISSIONS ACCOUNTED FOR BY 17 LARGE METRO AREAS, 1988-2002

Metropolitan areas accounting for at least 1\% of Black prison sentences, average 1987-2001

\begin{tabular}{|c|c|c|c|c|c|c|c|}
\hline & \multicolumn{4}{|c|}{ Black Proportion of National in NCRP $1988-2002$} & \multicolumn{3}{|c|}{ Ratio Prison to Population Proportion } \\
\hline Metro Area & Population & $\begin{array}{c}\text { Prison } \\
\text { Admissions }\end{array}$ & Revocations & $\begin{array}{c}\text { New } \\
\text { Sentences }\end{array}$ & $\begin{array}{c}\text { Prison } \\
\text { Admissions }\end{array}$ & Revocations & $\begin{array}{c}\text { New } \\
\text { Sentences }\end{array}$ \\
\hline Los Angeles CA & 0.037 & 0.085 & 0.144 & 0.048 & 2.286 & 3.876 & 1.301 \\
\hline $\begin{array}{l}\text { San Francisco \& Oakland } \\
\text { CA }\end{array}$ & 0.017 & 0.046 & 0.091 & 0.018 & 2.674 & 5.266 & 1.022 \\
\hline New York NY & 0.086 & 0.065 & 0.071 & 0.065 & 0.758 & 0.820 & 0.749 \\
\hline Northern New Jersey & 0.028 & 0.031 & 0.027 & 0.035 & 1.104 & 0.950 & 1.257 \\
\hline Philadelphia PA & 0.030 & 0.018 & 0.018 & 0.018 & 0.585 & 0.604 & 0.597 \\
\hline Chicago IL & 0.054 & 0.057 & 0.042 & 0.070 & 1.061 & 0.772 & 1.304 \\
\hline Detroit MI & 0.035 & 0.023 & 0.026 & 0.022 & 0.659 & 0.748 & 0.627 \\
\hline Cleveland $\mathrm{OH}$ & 0.014 & 0.012 & 0.003 & 0.018 & 0.812 & 0.205 & 1.261 \\
\hline Miami FL & 0.026 & 0.024 & 0.004 & 0.040 & 0.930 & 0.137 & 1.511 \\
\hline Tampa FL & 0.007 & 0.014 & 0.002 & 0.023 & 2.049 & 0.304 & 3.327 \\
\hline Orlando FL & 0.006 & 0.007 & 0.001 & 0.011 & 1.165 & 0.138 & 1.916 \\
\hline Jacksonville FL & 0.007 & 0.007 & 0.001 & 0.011 & 0.929 & 0.098 & 1.536 \\
\hline Atlanta GA & 0.033 & 0.025 & 0.029 & 0.023 & 0.761 & 0.881 & 0.711 \\
\hline Houston TX & 0.026 & 0.028 & 0.027 & 0.029 & 1.069 & 1.037 & 1.137 \\
\hline Dallas TX & 0.021 & 0.025 & 0.023 & 0.027 & 1.168 & 1.080 & 1.279 \\
\hline Virginia Beach VA & 0.016 & 0.010 & 0.006 & 0.014 & 0.647 & 0.391 & 0.849 \\
\hline Baltimore MD & 0.024 & 0.020 & 0.005 & 0.032 & 0.844 & 0.194 & 1.323 \\
\hline Sum of these & 0.469 & 0.497 & 0.518 & 0.505 & 1.062 & 1.105 & 1.078 \\
\hline
\end{tabular}

TABLE 2. PROPORTION OF WHITE POPULATION AND PRISON ADMISSIONS ACCOUNTED FOR BY 17 LARGE METRO AREAS, 1988-2002 
Metropolitan areas accounting for at least 1\% of Black prison sentences, average 1988-2001

\begin{tabular}{|c|c|c|c|c|c|c|c|}
\hline & \multicolumn{4}{|c|}{ White Proportion of National in NCRP 1987-2002 } & \multicolumn{3}{|c|}{ Ratio Prison to Population Proportion } \\
\hline Metro Area & Population & $\begin{array}{c}\text { Prison } \\
\text { Admissions }\end{array}$ & Revocations & $\begin{array}{c}\text { New } \\
\text { Sentences }\end{array}$ & $\begin{array}{c}\text { Prison } \\
\text { Admissions } \\
\end{array}$ & Revocations & $\begin{array}{c}\text { New } \\
\text { Sentences }\end{array}$ \\
\hline Los Angeles CA & 0.035 & 0.066 & 0.107 & 0.042 & 1.882 & 3.053 & 1.206 \\
\hline $\begin{array}{l}\text { San Francisco \& Oakland } \\
\text { CA }\end{array}$ & 0.015 & 0.023 & 0.044 & 0.011 & 1.521 & 2.838 & 0.735 \\
\hline New York NY & 0.043 & 0.014 & 0.014 & 0.015 & 0.327 & 0.328 & 0.341 \\
\hline Northern New Jersey & 0.028 & 0.012 & 0.008 & 0.015 & 0.420 & 0.293 & 0.520 \\
\hline Philadelphia PA & 0.018 & 0.005 & 0.005 & 0.006 & 0.302 & 0.299 & 0.317 \\
\hline Chicago IL & 0.032 & 0.015 & 0.009 & 0.020 & 0.482 & 0.275 & 0.638 \\
\hline Detroit MI & 0.020 & 0.014 & 0.013 & 0.015 & 0.688 & 0.673 & 0.728 \\
\hline Cleveland $\mathrm{OH}$ & 0.011 & 0.006 & 0.002 & 0.010 & 0.612 & 0.157 & 0.935 \\
\hline Miami FL & 0.016 & 0.014 & 0.001 & 0.022 & 0.845 & 0.083 & 1.376 \\
\hline Tampa FL & 0.011 & 0.017 & 0.002 & 0.027 & 1.522 & 0.137 & 2.488 \\
\hline Orlando FL & 0.006 & 0.006 & 0.000 & 0.011 & 1.085 & 0.082 & 1.783 \\
\hline Jacksonville FL & 0.004 & 0.005 & 0.000 & 0.008 & 1.100 & 0.093 & 1.802 \\
\hline Atlanta GA & 0.014 & 0.020 & 0.025 & 0.017 & 1.395 & 1.741 & 1.231 \\
\hline Houston TX & 0.014 & 0.019 & 0.015 & 0.022 & 1.369 & 1.084 & 1.615 \\
\hline Dallas TX & 0.017 & 0.024 & 0.019 & 0.028 & 1.456 & 1.169 & 1.707 \\
\hline Virginia Beach VA & 0.006 & 0.004 & 0.002 & 0.006 & 0.710 & 0.368 & 0.962 \\
\hline Baltimore MD & 0.011 & 0.007 & 0.002 & 0.011 & 0.646 & 0.151 & 0.996 \\
\hline Sum of these & 0.300 & 0.271 & 0.269 & 0.285 & 0.905 & 0.896 & 0.951 \\
\hline
\end{tabular}

TABLE 3. PROPORTION OF HISPANIC POPULATION AND PRISON ADMISSIONS ACCOUNTED FOR BY 17 LARGE METRO AREAS, 1988-2002 
Metropolitan areas accounting for at least 1\% of Black prison sentences, average 1987-2001

\begin{tabular}{|c|c|c|c|c|c|c|c|}
\hline & \multicolumn{4}{|c|}{ Hispanic Proportion of National in NCRP $1988-2002$} & \multicolumn{3}{|c|}{ Ratio Prison to Population Proportion } \\
\hline Metro Area & Population & $\begin{array}{c}\text { Prison } \\
\text { Admissions }\end{array}$ & Revocations & $\begin{array}{c}\text { New } \\
\text { Sentences }\end{array}$ & $\begin{array}{c}\text { Prison } \\
\text { Admissions } \\
\end{array}$ & Revocations & $\begin{array}{c}\text { New } \\
\text { Sentences }\end{array}$ \\
\hline Los Angeles CA & 0.160 & 0.249 & 0.293 & 0.218 & 1.556 & 1.825 & 1.359 \\
\hline $\begin{array}{l}\text { San Francisco \& Oakland } \\
\text { CA }\end{array}$ & 0.034 & 0.029 & 0.039 & 0.021 & 0.833 & 1.134 & 0.609 \\
\hline New York NY & 0.089 & 0.130 & 0.111 & 0.145 & 1.468 & 1.250 & 1.636 \\
\hline Northern New Jersey & 0.032 & 0.024 & 0.015 & 0.031 & 0.750 & 0.479 & 0.955 \\
\hline Philadelphia PA & 0.005 & 0.008 & 0.005 & 0.009 & 1.461 & 1.041 & 1.782 \\
\hline Chicago IL & 0.039 & 0.022 & 0.010 & 0.032 & 0.574 & 0.262 & 0.811 \\
\hline Detroit MI & 0.004 & 0.001 & 0.001 & 0.001 & 0.207 & 0.155 & 0.247 \\
\hline Cleveland $\mathrm{OH}$ & 0.002 & 0.001 & 0.000 & 0.002 & 0.481 & 0.090 & 0.777 \\
\hline Miami FL & 0.052 & 0.017 & 0.002 & 0.027 & 0.316 & 0.042 & 0.523 \\
\hline Tampa FL & 0.010 & 0.004 & 0.000 & 0.006 & 0.364 & 0.032 & 0.615 \\
\hline Orlando FL & 0.008 & 0.002 & 0.000 & 0.004 & 0.300 & 0.017 & 0.514 \\
\hline Jacksonville FL & 0.003 & 0.000 & 0.000 & 0.001 & 0.116 & 0.017 & 0.190 \\
\hline Atlanta GA & 0.006 & 0.001 & 0.001 & 0.002 & 0.246 & 0.095 & 0.361 \\
\hline Houston TX & 0.043 & 0.027 & 0.014 & 0.036 & 0.621 & 0.330 & 0.841 \\
\hline Dallas TX & 0.037 & 0.020 & 0.010 & 0.027 & 0.527 & 0.272 & 0.721 \\
\hline Virginia Beach VA & 0.002 & 0.000 & 0.000 & 0.000 & 0.040 & 0.018 & 0.055 \\
\hline Baltimore MD & 0.002 & 0.000 & 0.000 & 0.000 & 0.000 & 0.000 & 0.000 \\
\hline Sum of these & 0.528 & 0.535 & 0.502 & 0.561 & 1.012 & 0.950 & 1.063 \\
\hline
\end{tabular}

TABLE 4. SUMMARY OF PRISON SENTENCE PATTERNS IN THE SEVENTEEN LARGE METRO AREAS VERSUS OTHER AREAS, 1988-2001 
Summary of patterns in the seventeen large metro areas versus other areas, 1988-2001

\begin{tabular}{|c|c|c|c|c|}
\hline & Big Metro & & Other & \\
\hline & Black & White & Black & White \\
\hline Drugs & $\begin{array}{l}\text { Rise through } 1990, \\
\text { then decline to } \\
1993, \text { then flat }\end{array}$ & $\begin{array}{l}\text { Small rise through } \\
1990, \text { small } \\
\text { decline to } 1993, \\
\text { then small rise }\end{array}$ & $\begin{array}{l}\text { Rise through } 1990 \\
\text { then flat }\end{array}$ & $\begin{array}{l}\text { Small rise through } \\
\text { 1990, smaller } \\
\text { decline to } 1994, \\
\text { then steep rise } \\
\text { after } 1995\end{array}$ \\
\hline Violence & $\begin{array}{l}\text { Rise through } 1991 \\
\text { then modest } \\
\text { decline (1995 } \\
\text { bump) }\end{array}$ & $\begin{array}{l}\text { Mostly flat; slight } \\
\text { rise in } 1995 \text { to } \\
\text { new plateau }\end{array}$ & Steady rise & Steady rise \\
\hline Rob/burg & $\begin{array}{l}\text { Rise through } 1990 \\
\text { then steep decline }\end{array}$ & $\begin{array}{l}\text { Steady decline } \\
\text { after } 1989\end{array}$ & Mostly flat & Mostly flat \\
\hline Theft & $\begin{array}{l}\text { General decline } \\
\text { (1995 bump), } \\
\text { lower than other }\end{array}$ & $\begin{array}{l}\text { Steady modest } \\
\text { decline (1995 } \\
\text { bump) }\end{array}$ & $\begin{array}{l}\text { Slight decline, } \\
\text { relatively steady \% } \\
\text { of total }\end{array}$ & Flat until 2001 rise \\
\hline Other & $\begin{array}{l}\text { Steady to } 1995 \\
\text { then decline, } 2001 \\
\text { bump (Texas) }\end{array}$ & Flat & Steady rise & Steady rise \\
\hline
\end{tabular}

TABLE 5. SUMMARY OF PRISON ADMISSION TRENDS BY RACE, OFFENSE AND AREA TYPES, 1988-2001 
Summary of prison admission trends by race, offense and area types, 1988-2001. Comparisons are rates within race.

\begin{tabular}{|c|c|c|c|c|c|c|c|c|}
\hline & Black & & & & White & & & \\
\hline & $\begin{array}{l}2 \text { metro } \\
B>15 \%\end{array}$ & $\begin{array}{l}3 \text { metro } \\
B<15 \%\end{array}$ & 4 rural $B<5 \%$ & 5 rural $B>8 \%$ & $\begin{array}{l}2 \text { metro } \\
B>15 \%\end{array}$ & $\begin{array}{l}3 \text { metro } \\
\mathrm{B}<15 \%\end{array}$ & 4 rural $B<5 \%$ & 5 rural $B>8 \%$ \\
\hline Theft & $\begin{array}{l}\text { Moderate } \\
\text { declining }\end{array}$ & High declining & $\begin{array}{l}\text { Low to high to } \\
\text { moderate }\end{array}$ & Low oscillate & High stable & Low declining & Low rising & $\begin{array}{l}\text { Highest, } \\
\text { declining } \\
\text { some }\end{array}$ \\
\hline Rob/burg & Low stable & High declining & Low rising & $\begin{array}{l}\text { Low slight } \\
\text { decline }\end{array}$ & $\begin{array}{l}\text { Declined from } \\
\text { moderate to } \\
\text { similar to } \\
\text { other metro }\end{array}$ & Stable low & Stable low & $\begin{array}{l}\text { Highest, } \\
\text { declined } \\
\text { through } 1994 \\
\text { then rose to } \\
\text { stable }\end{array}$ \\
\hline Violence & Low, stable & High stable & $\begin{array}{l}\text { Rising from } \\
\text { lowest to } \\
\text { highest }\end{array}$ & Low stable & $\begin{array}{l}\text { Low rising } \\
\text { slightly }\end{array}$ & $\begin{array}{l}\text { Moderate } \\
\text { rising }\end{array}$ & High rising & $\begin{array}{l}\text { Highest, rising } \\
\text { after } 1995\end{array}$ \\
\hline Other & Low stable & $\begin{array}{l}\text { High stable, } \\
\text { rising after } \\
1999\end{array}$ & $\begin{array}{l}\text { Rising from } \\
\text { lowest to } \\
\text { highest }\end{array}$ & Low stable & $\begin{array}{l}\text { Rising but } \\
\text { lower, similar } \\
\text { to } 3 \text { after } \\
1994\end{array}$ & $\begin{array}{l}\text { Rising but } \\
\text { lower, similar } \\
\text { to } 2 \text { after } \\
1994\end{array}$ & $\begin{array}{l}\text { Rising from } \\
\text { lowest to } \\
\text { second } \\
\text { highest }\end{array}$ & $\begin{array}{l}\text { Highest, rising } \\
\text { after } 1995\end{array}$ \\
\hline Drug & $\begin{array}{l}\text { Low stable, } \\
\text { after } 1990\end{array}$ & $\begin{array}{l}\text { High stable } \\
\text { after } 1990\end{array}$ & $\begin{array}{l}\text { Rising from } \\
\text { lowest to } \\
\text { highest }\end{array}$ & $\begin{array}{l}2^{\text {nd }} \text { lowest, } \\
\text { stable after } \\
1990\end{array}$ & $\begin{array}{l}\text { Curvlinear: } \\
\text { moderate } \\
\text { declining then } \\
\text { rising, ends as } \\
\text { lowest group }\end{array}$ & Rising & $\begin{array}{l}\text { Rising lowest } \\
\text { to highest }\end{array}$ & $\begin{array}{l}\text { Curvlinear: } \\
\text { highest to } \\
\text { lowest to } \\
\text { highest }\end{array}$ \\
\hline
\end{tabular}

TABLE 6. REGRESSION OF AVERAGE PRISON ADMISSION RATE (SQUARE ROOT) ON AREA TYPE 
Regression of average prison admission rate (square root) on racial demographics and urbanity, metro \& non-metro areas

\begin{tabular}{|c|c|c|c|c|c|c|c|c|c|c|c|}
\hline \multirow[b]{2}{*}{ White } & \multicolumn{2}{|c|}{ Log Black pop } & \multicolumn{2}{|l|}{$\%$ Black } & \multicolumn{2}{|l|}{$\%$ Hisp } & \multicolumn{2}{|l|}{ Non-metro } & \multicolumn{3}{|l|}{ Constant } \\
\hline & $\mathrm{b}$ & se & $\mathrm{b}$ & se & $\mathrm{b}$ & se & $b$ & se & $\mathrm{b}$ & se & R2 \\
\hline All admissions & -0.458 & {$[0.330]$} & 3.786 & [2.835] & $11.83^{* * *}$ & [2.001] & 0.636 & {$[0.651]$} & $11.20 * * *$ & [1.248] & 0.131 \\
\hline Revocations & -0.507 & [0.359] & 0.399 & [3.083] & $10.68 * * *$ & [2.176] & 0.32 & {$[0.708]$} & $7.132 * * *$ & [1.357] & 0.112 \\
\hline New sentences & -0.234 & {$[0.225]$} & $5.349 * * *$ & [1.931] & $6.330 * * *$ & [1.363] & 0.606 & {$[0.443]$} & $8.340^{* * *}$ & [0.850] & 0.093 \\
\hline Drug & 0.0016 & {$[0.130]$} & 1.633 & [1.116] & $5.659 * * *$ & {$[0.788]$} & 0.36 & {$[0.256]$} & $2.859 * * *$ & [0.491] & 0.177 \\
\hline Violence & -0.083 & [0.0947] & 0.42 & [0.813] & $2.024 * * *$ & [0.574] & 0.279 & [0.187] & $4.125 * * *$ & [0.358] & 0.057 \\
\hline Rob/burg & 0.051 & {$[0.112]$} & $2.803^{* * *}$ & [0.961] & $2.841^{* * *}$ & [0.679] & 0.0492 & {$[0.221]$} & $3.140 * * *$ & [0.423] & 0.108 \\
\hline Theft & $-0.212 *$ & {$[0.123]$} & $5.221 * * *$ & [1.053] & $1.492 * *$ & {$[0.743]$} & 0.22 & {$[0.242]$} & $3.631^{* * *}$ & [0.463] & 0.107 \\
\hline Other & -0.147 & [0.119] & 1.526 & [1.022] & $1.484^{* *}$ & {$[0.721]$} & $0.430 *$ & {$[0.235]$} & $4.061 * * *$ & {$[0.450]$} & 0.029 \\
\hline \multicolumn{12}{|l|}{ Black } \\
\hline All admissions & -1.26 & {$[0.943]$} & $-35.04^{* * *}$ & [8.101] & 8.341 & [5.718] & $-5.844 * * *$ & {$[1.861]$} & $42.07 * * *$ & [3.565] & 0.22 \\
\hline Revocations & $-1.936 *$ & [1.129] & $-22.40 * *$ & [9.597] & $24.44 * * *$ & [7.203] & -3.543 & [2.179] & $28.61^{* * *}$ & [4.229] & 0.166 \\
\hline New sentences & -1.009 & {$[0.623]$} & $-19.66 * * *$ & [5.353] & -5.651 & [3.778] & $-4.420 * * *$ & [1.229] & $32.83 * * *$ & [2.356] & 0.178 \\
\hline Drug & 0.608 & [0.509] & $-14.74 * * *$ & [4.371] & -2.641 & [3.085] & $-3.068 * * *$ & [1.004] & $14.07 * * *$ & [1.924] & 0.074 \\
\hline Violence & $-1.163 * * *$ & {$[0.275]$} & $-9.906 * * *$ & [2.364] & -2.055 & [1.669] & $-1.225 * *$ & {$[0.543]$} & $17.27 * * *$ & [1.040] & 0.307 \\
\hline Rob/burg & 0.0903 & [0.292] & $-6.768 * * *$ & [2.509] & 1.961 & {$[1.771]$} & $-2.790 * * *$ & {$[0.576]$} & $11.94^{* * *}$ & [1.104] & 0.135 \\
\hline Theft & $-1.133^{* * *}$ & [0.337] & 0.446 & [2.841] & -1.905 & [2.132] & -1.025 & [0.645] & $14.22 * * *$ & [1.264] & 0.088 \\
\hline Other & $-1.032 * * *$ & {$[0.275]$} & $-6.635 * * *$ & [2.359] & $-4.827 * * *$ & [1.665] & $-0.913^{*}$ & {$[0.542]$} & $14.59 * * *$ & [1.038] & 0.217 \\
\hline \multicolumn{12}{|l|}{ Disparity } \\
\hline All admissions & 0.0228 & [0.0246] & $-1.616 * * *$ & {$[0.211]$} & $-0.755^{* * *}$ & [0.149] & $-0.253 * * *$ & [0.0485] & $1.292 * * *$ & [0.0929] & 0.311 \\
\hline Revocations & $0.0720 * *$ & [0.0288] & $-1.816^{* * *}$ & {$[0.245]$} & $-0.694^{* * *}$ & [0.184] & $-0.267 * * *$ & [0.0556] & $1.162 * * *$ & [0.108] & 0.247 \\
\hline New sentences & -0.00931 & [0.0249] & $-1.527 * * *$ & [0.214] & $-0.900 * * *$ & [0.151] & $-0.259 * * *$ & [0.0492] & $1.407 * * *$ & [0.0942] & 0.339 \\
\hline Drug & 0.046 & [0.0389] & $-1.598 * * *$ & [0.334] & $-1.645^{* * *}$ & {$[0.236]$} & $-0.330 * * *$ & [0.0768] & $1.568 * * *$ & [0.147] & 0.227 \\
\hline Violence & $-0.0497^{*}$ & {$[0.0266]$} & $-1.214 * * *$ & {$[0.228]$} & $-0.579 * * *$ & [0.161] & $-0.197 * * *$ & [0.0524] & $1.405^{* * *}$ & [0.100] & 0.271 \\
\hline Rob/burg & -0.00531 & {$[0.0250]$} & $-1.367 * * *$ & [0.215] & $-0.512 * * *$ & [0.152] & $-0.291 * * *$ & [0.0493] & $1.328 * * *$ & [0.0945] & 0.293 \\
\hline Theft & -0.0258 & [0.0280] & $-1.622 * * *$ & {$[0.236]$} & $-0.859 * * *$ & [0.177] & $-0.194 * * *$ & [0.0536] & $1.344^{* * *}$ & [0.105] & 0.321 \\
\hline Other & $-0.0598 * *$ & [0.0301] & $-1.306 * * *$ & [0.259] & $-0.939 * * *$ & [0.183] & $-0.221 * * *$ & [0.0594] & $1.357 * * *$ & [0.114] & 0.278 \\
\hline
\end{tabular}


Regression of change 1988-1992 to 1998-2001 in average prison admission rate (square root) on area type

\begin{tabular}{|c|c|c|c|c|c|c|c|c|c|c|c|}
\hline \multirow[b]{2}{*}{ White } & \multicolumn{2}{|c|}{ Log Black pop } & \multirow{2}{*}{$\begin{array}{c}\% \text { Black } \\
\text { b }\end{array}$} & \multicolumn{3}{|c|}{$\%$ Hisp } & \multicolumn{2}{|c|}{ Non-metro } & \multirow{2}{*}{$\begin{array}{c}\text { Constant } \\
\text { b }\end{array}$} & \multirow[b]{2}{*}{ se } & \multirow[b]{2}{*}{$\mathrm{R} 2$} \\
\hline & $b$ & se & & se & $b$ & se & $b$ & se & & & \\
\hline All admissions & $-0.968 * * *$ & [0.231] & 0.914 & [1.988] & $13.19 * * *$ & [1.403] & $1.147 * *$ & [0.457] & $4.177^{* * *}$ & {$[0.875]$} & 0.351 \\
\hline New sentences & $-1.031 * * *$ & [0.182] & $3.949 * *$ & [1.565] & $9.243 * * *$ & [1.105] & $1.122 * * *$ & [0.359] & $3.836^{* * *}$ & [0.689] & 0.312 \\
\hline Drug & $-0.607 * * *$ & [0.135] & $1.953^{*}$ & [1.157] & $6.820 * * *$ & [0.817] & $0.840 * * *$ & {$[0.266]$} & $2.178 * * *$ & [0.509] & 0.295 \\
\hline Violence & $-0.348 * * *$ & [0.0720] & $1.440 * *$ & [0.619] & $5.387^{* * *}$ & [0.437] & $0.382 * * *$ & [0.142] & $1.361^{* * *}$ & [0.272] & 0.433 \\
\hline Theft & $-0.382 * * *$ & [0.106] & $1.787^{*}$ & [0.915] & $-1.168^{*}$ & [0.646] & 0.327 & {$[0.210]$} & $1.384 * * *$ & [0.403] & 0.072 \\
\hline Other & $-0.329 * * *$ & [0.113] & 0.333 & [0.969] & $2.625^{* * *}$ & [0.684] & 0.366 & [0.222] & $1.772 * * *$ & {$[0.426]$} & 0.116 \\
\hline \multicolumn{12}{|l|}{ Black } \\
\hline All admissions & $-3.408 * * *$ & [0.822] & -6.07 & [7.064] & - 7.342 & [4.986] & 2.205 & [1.622] & $17.36 * * *$ & [3.109] & 0.146 \\
\hline Revocations & $-1.563^{* *}$ & [0.723] & $-13.15^{* *}$ & [6.143] & 0.71 & [4.610] & 0.901 & [1.395] & $10.81 * * *$ & [2.707] & 0.108 \\
\hline Rob/burg & $-0.930 * * *$ & [0.326] & 3.832 & [2.799] & -1.794 & [1.976] & $1.516 * *$ & [0.643] & $2.140^{*}$ & [1.232] & 0.054 \\
\hline Theft & -0.29 & [0.363] & 2.589 & [3.062] & $-4.329 *$ & [2.298] & $1.351^{*}$ & [0.695] & -0.485 & [1.363] & 0.039 \\
\hline Other & -0.0765 & [0.352] & $-6.426 * *$ & [3.027] & $-7.710 * * *$ & [2.137] & -0.431 & [0.695] & $2.288^{*}$ & [1.332] & 0.069 \\
\hline \multicolumn{12}{|l|}{ Disparity } \\
\hline All admissions & 0.00254 & [0.0177] & $-0.333^{* *}$ & [0.152] & $-1.372^{* * *}$ & [0.107] & -0.0186 & [0.0349] & 0.071 & [0.0669] & 0.407 \\
\hline Revocations & -0.0327 & [0.0274] & -0.266 & [0.233] & $-1.096 * * *$ & [0.175] & 0.0319 & [0.0529] & $0.264 * *$ & [0.1030] & 0.163 \\
\hline New sentences & 0.0326 & [0.0200] & $-0.401 * *$ & [0.172] & $-1.402 * * *$ & [0.122] & -0.0218 & [0.0396] & -0.079 & [0.0758] & 0.361 \\
\hline Drug & 0.0244 & [0.0411] & -0.4 & [0.353] & $-2.216 * * *$ & [0.249] & -0.105 & {$[0.0811]$} & 0.0994 & [0.1550] & 0.250 \\
\hline Violence & $0.0482^{* *}$ & [0.0243] & $-0.510^{* *}$ & [0.209] & $-1.457^{* * *}$ & [0.147] & -0.00474 & [0.0479] & -0.125 & [0.0918] & 0.298 \\
\hline
\end{tabular}




\section{List of Figures}




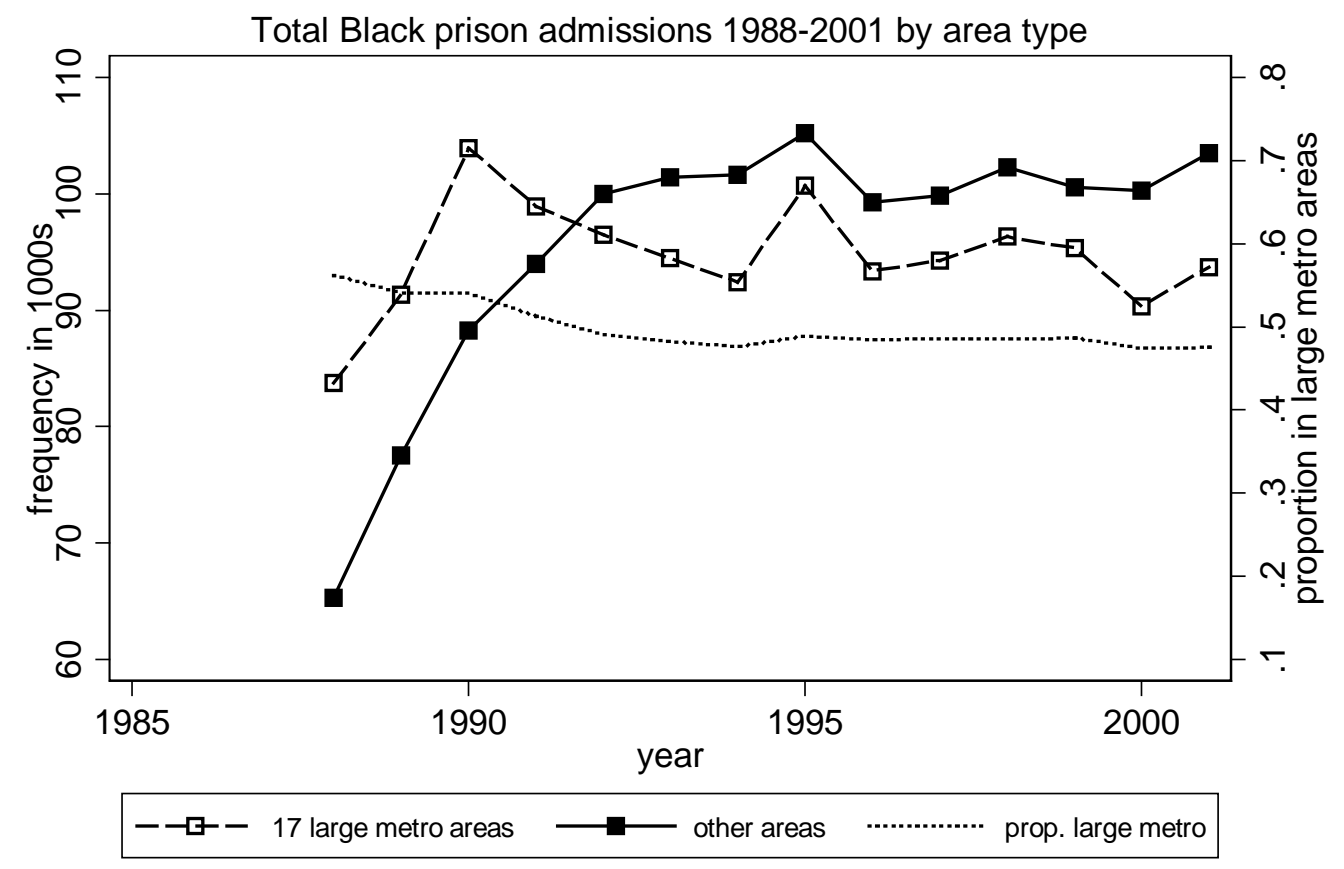

Areas with complete prison admission data only.

Large areas account for at least .01 of Black new sentences.

FIGURE 1. TOTAL BLACK PRISON ADMISSIONS 1988-2001 BY AREA TYPE 


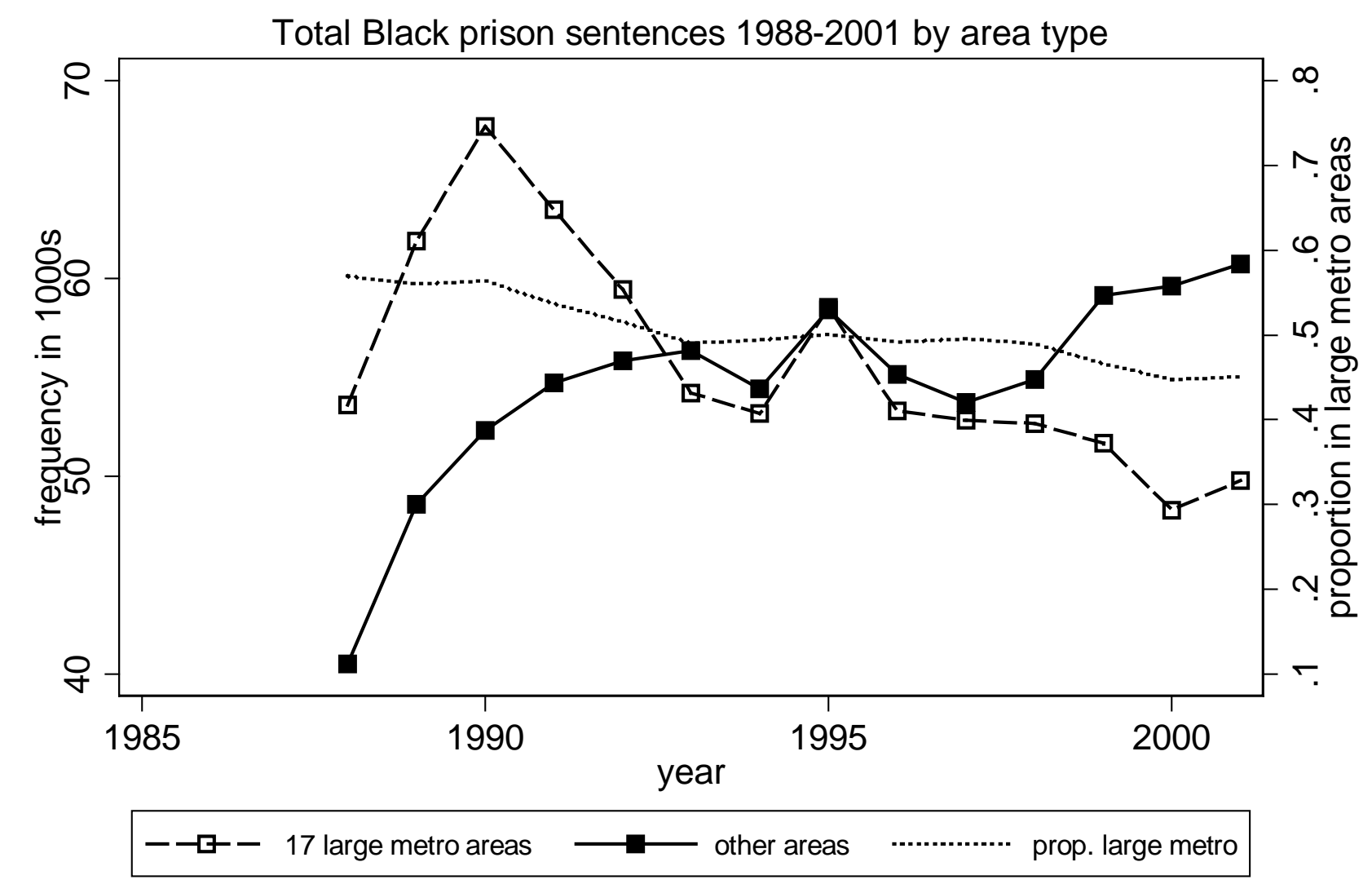

Areas with complete prison admission data only.

Large areas account for at least .01 of Black new sentences.

FIGURE 2. TOTAL BLACK PRISON SENTENCES 1988-2001 BY AREA TYPE 


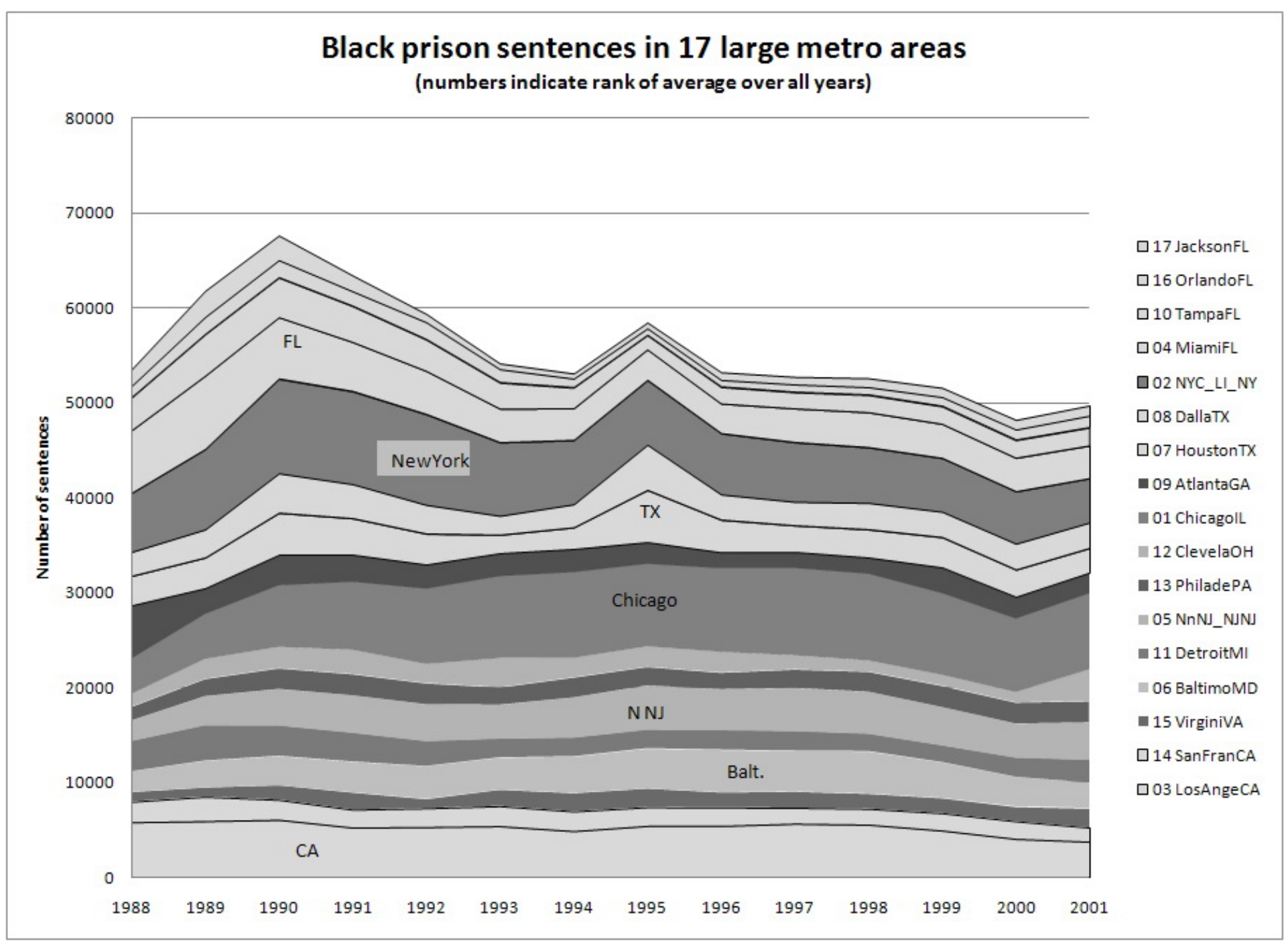

FIGURE 3. BLACK PRISON SENTENCES IN 17 LARGE METRO AREAS 1988-2001 
Total Black drug sentences $1988-2001$ by area type

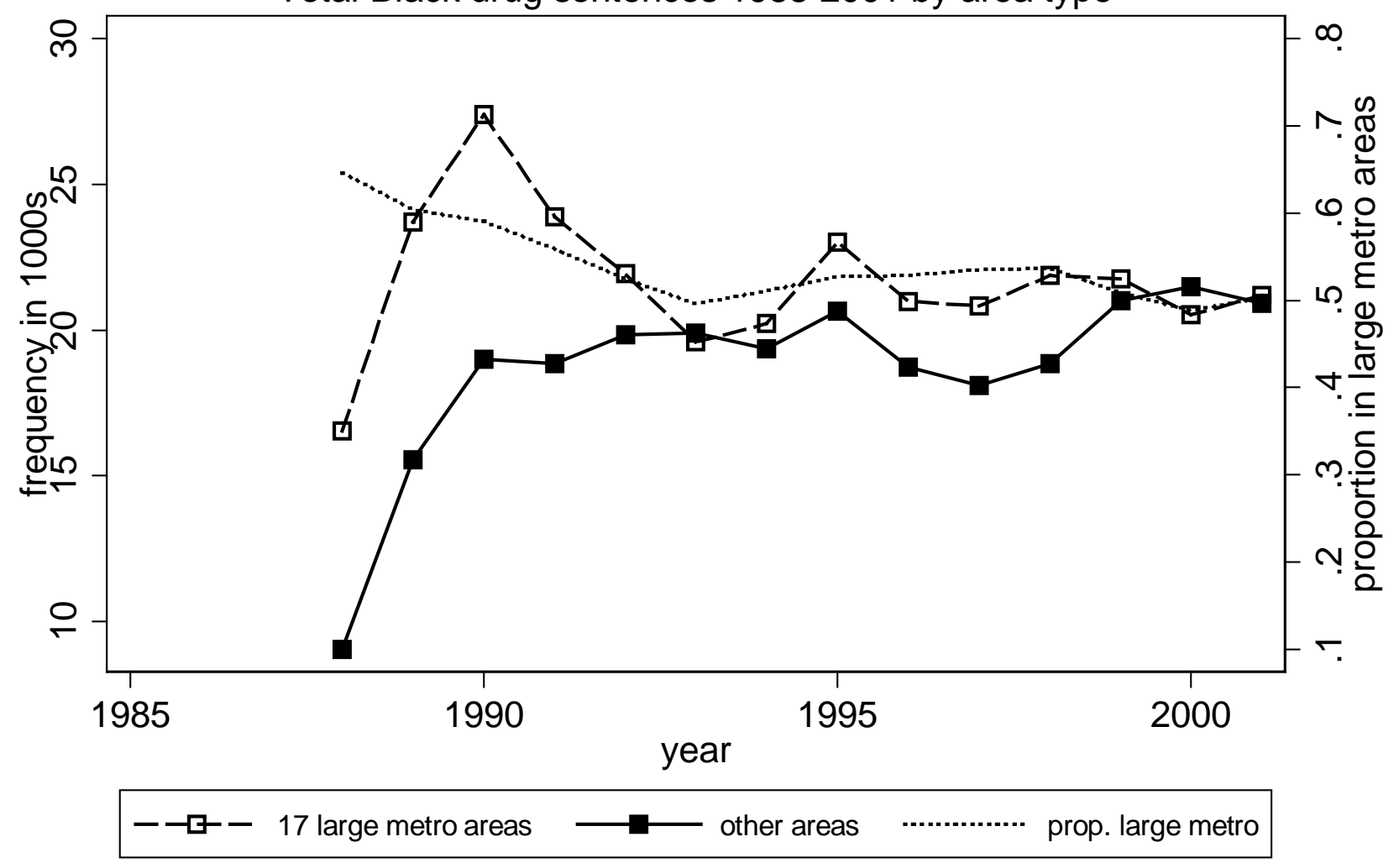

Areas with complete prison admission data only.

Large areas account for at least .01 of Black new sentences.

FIGURE 4. BLACK DRUG SENTENCES 1988-2001 BY AREA TYPE 


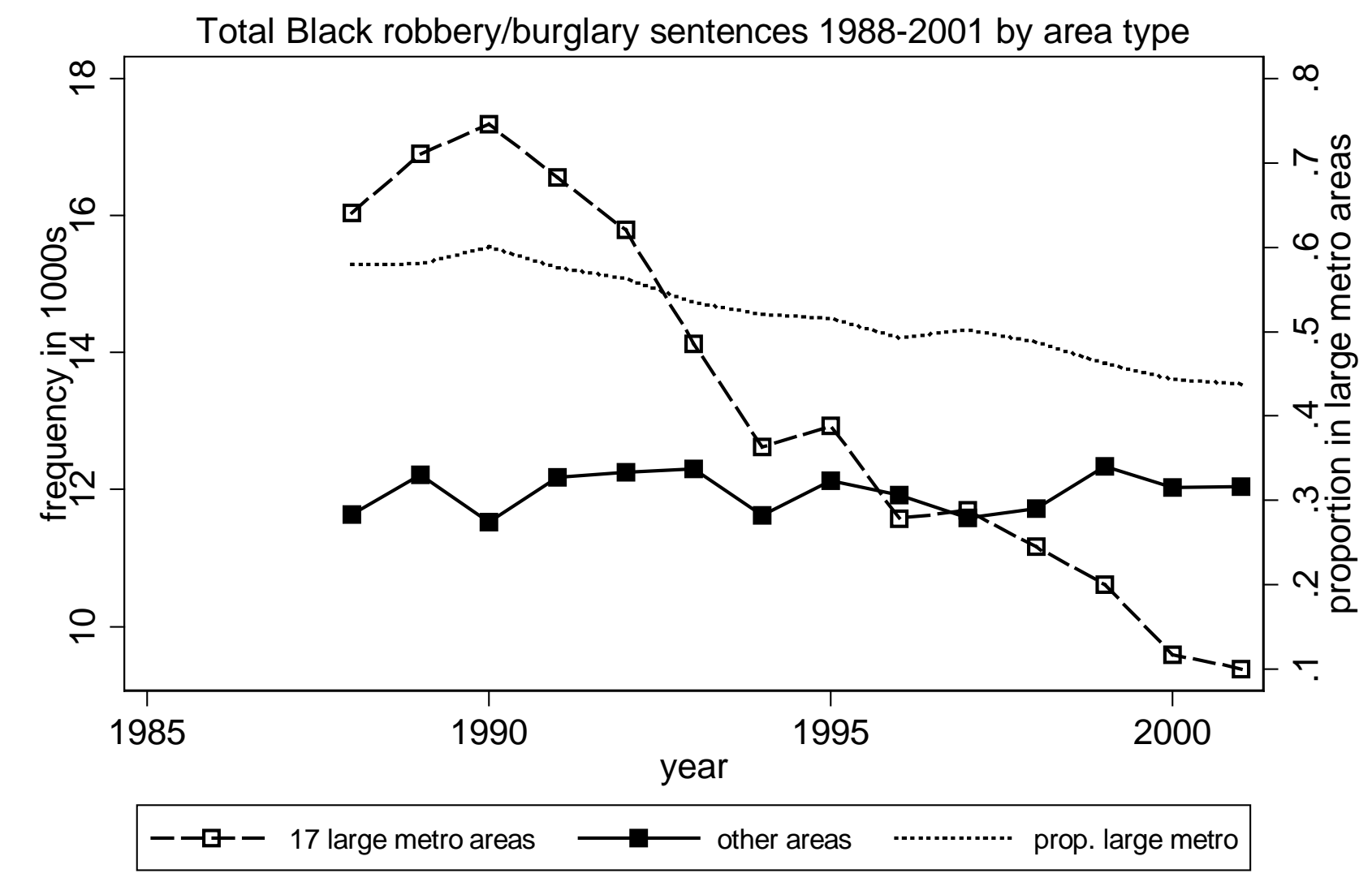

Areas with complete prison admission data only.

Large areas account for at least .01 of Black new sentences.

FIGURE 5. BLACK ROBBERY/BURGLARY SENTENCES 1988-2001 BY AREA TYPE 
Total Black violence sentences $1988-2001$ by area type

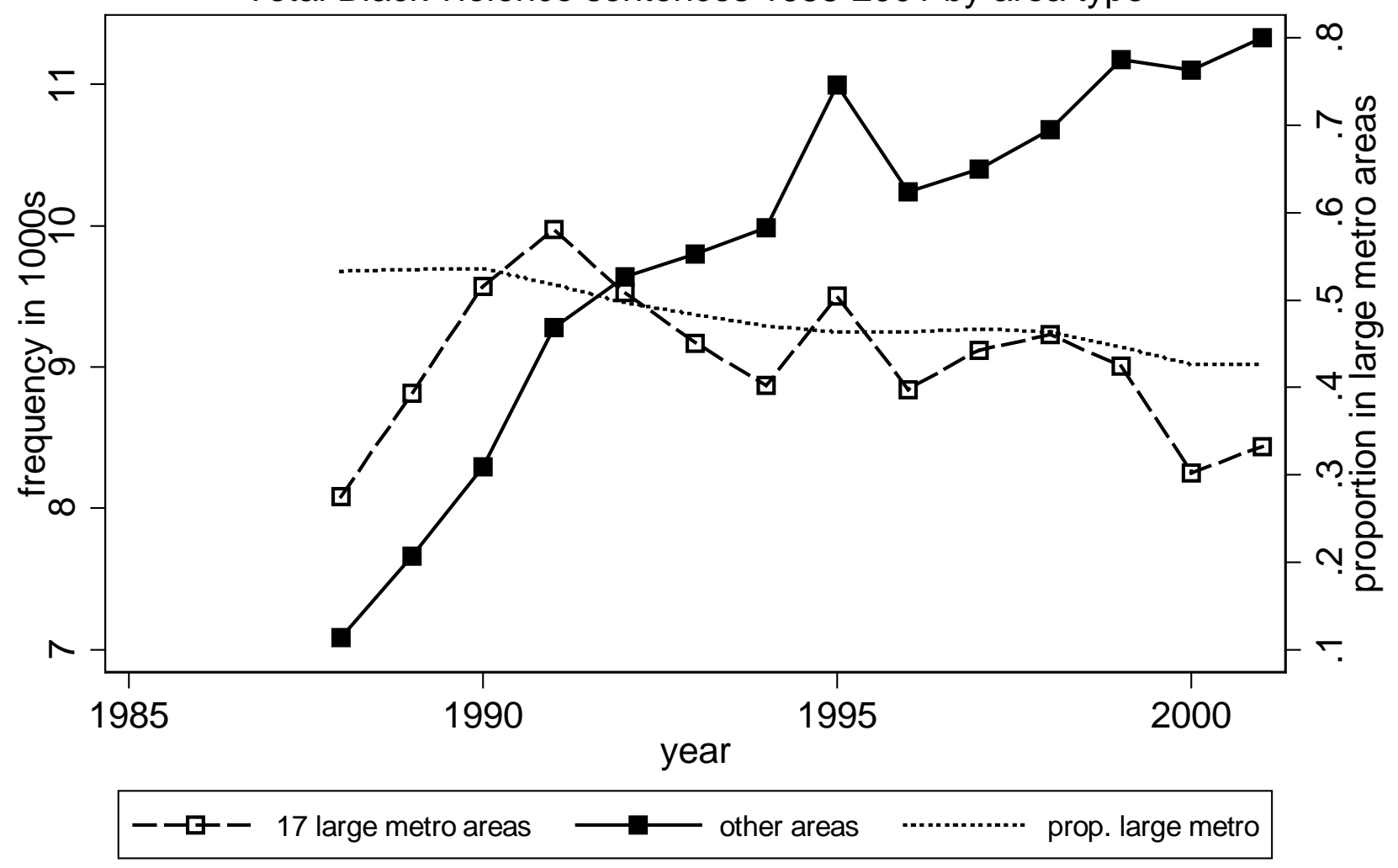

Areas with complete prison admission data only.

Large areas account for at least .01 of Black new sentences.

FIGURE 6. BLACK VIOLENCE SENTENCES 1988-2001 BY AREA TYPE 
Total Black theft sentences $1988-2001$ by area type

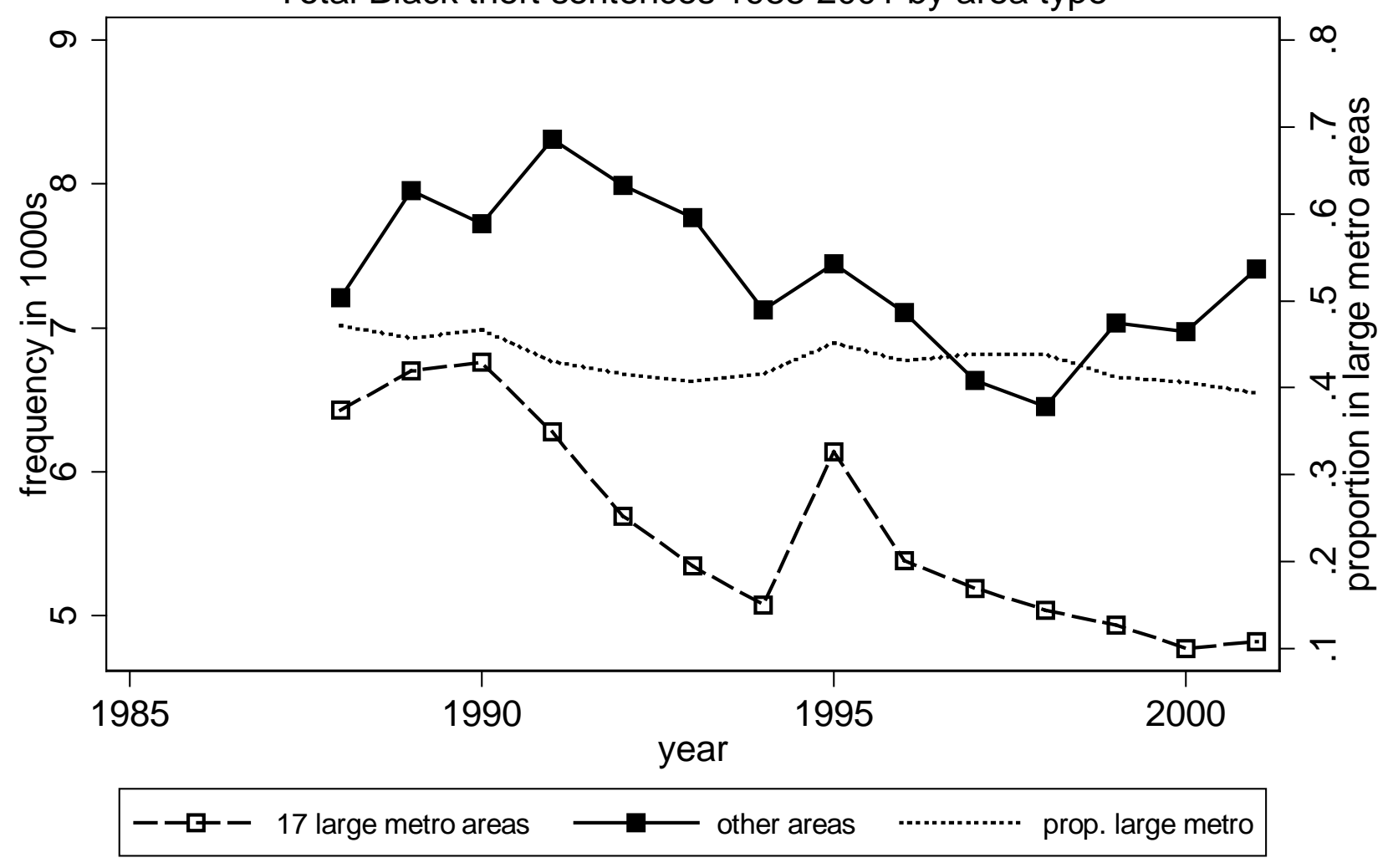

Areas with complete prison admission data only.

Large areas account for at least .01 of Black new sentences.

FIGURE 7. BLACK THEFT SENTENCES 1988-2001 BY AREA TYPE 


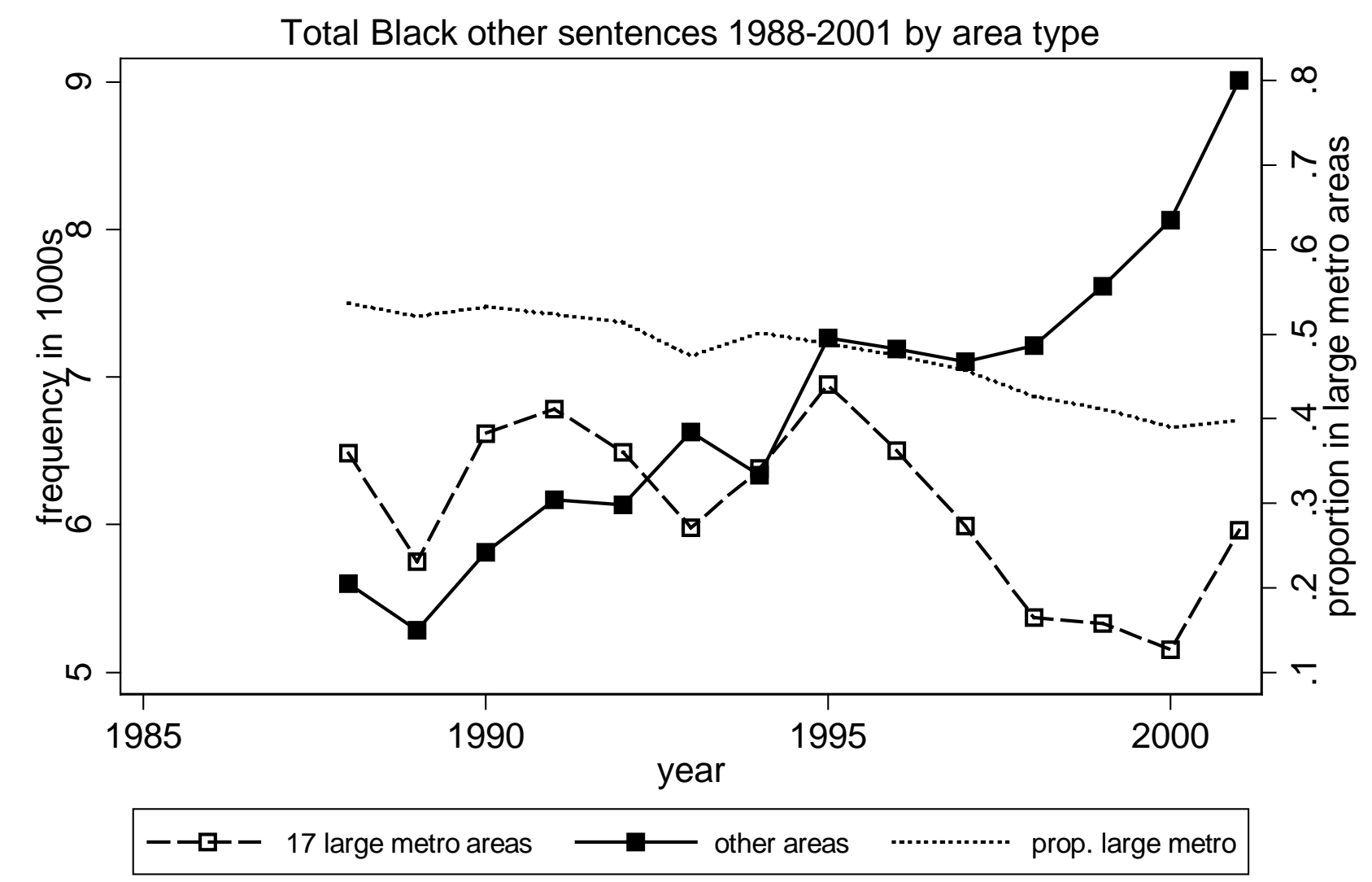

Areas with complete prison admission data only.

Large areas account for at least .01 of Black new sentences.

FIGURE 8. BLACK OTHER OFFENSE SENTENCES 1988-2001 BY AREA TYPE 


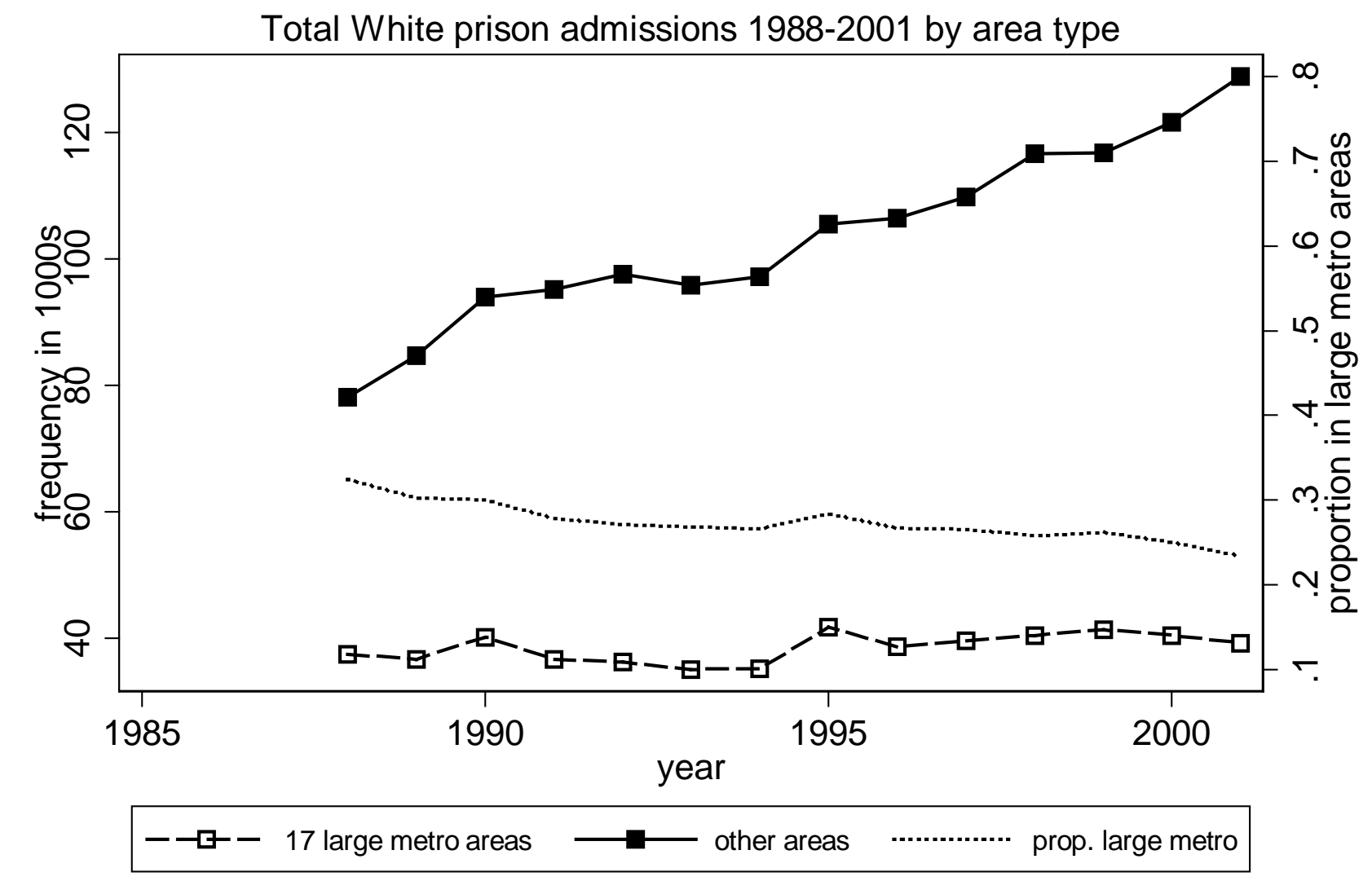

Areas with complete prison admission data only.

Large areas account for at least .01 of Black new sentences.

FIGURE 9. TOTAL WHITE PRISON ADMISSIONS 1988-2001 BY AREA TYPE 


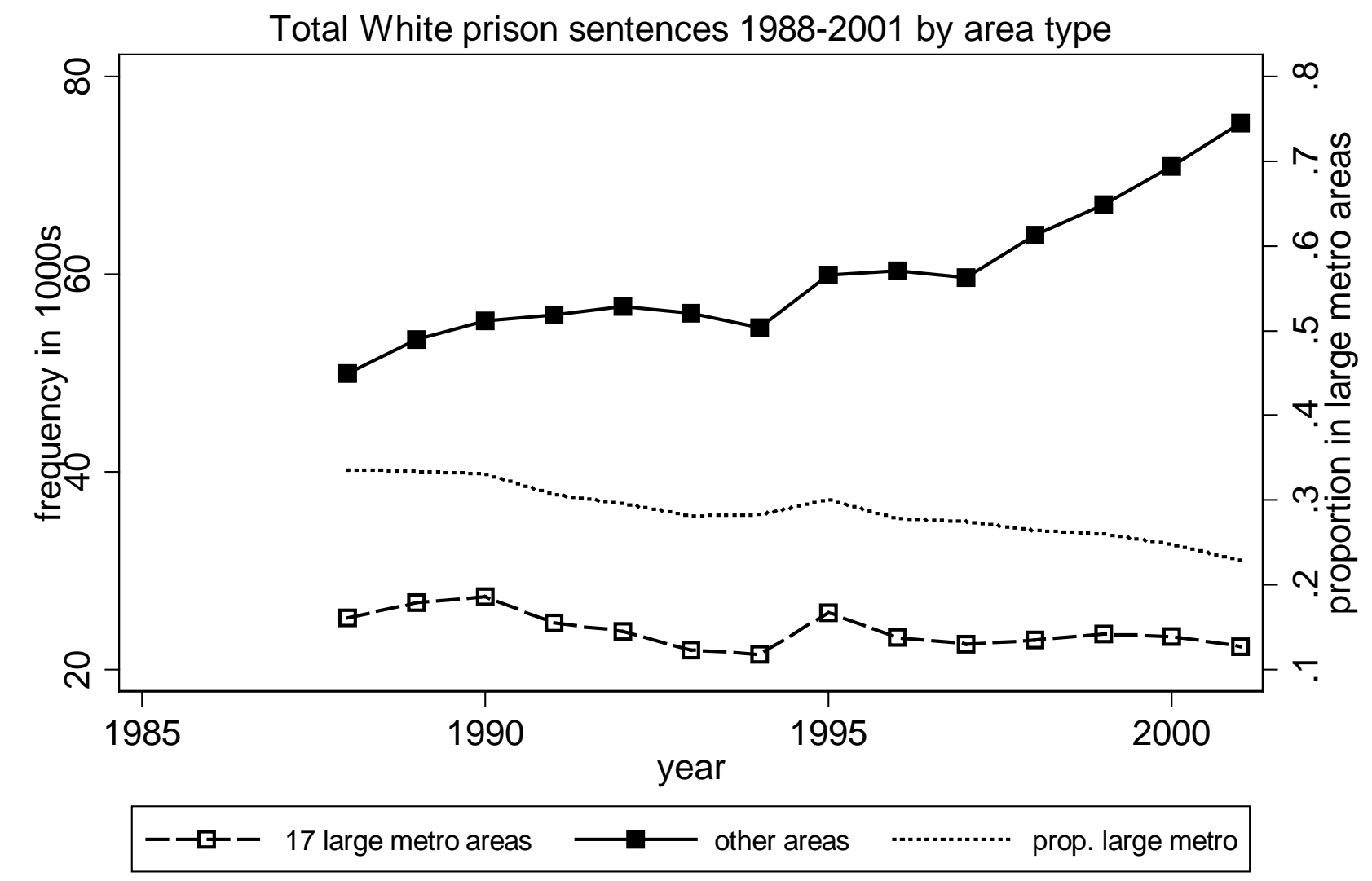

Areas with complete prison admission data only.

Large areas account for at least .01 of Black new sentences.

FIGURE 10. TOTAL WHITE PRISON SENTENCES 1988-2001 BY AREA TYPE 


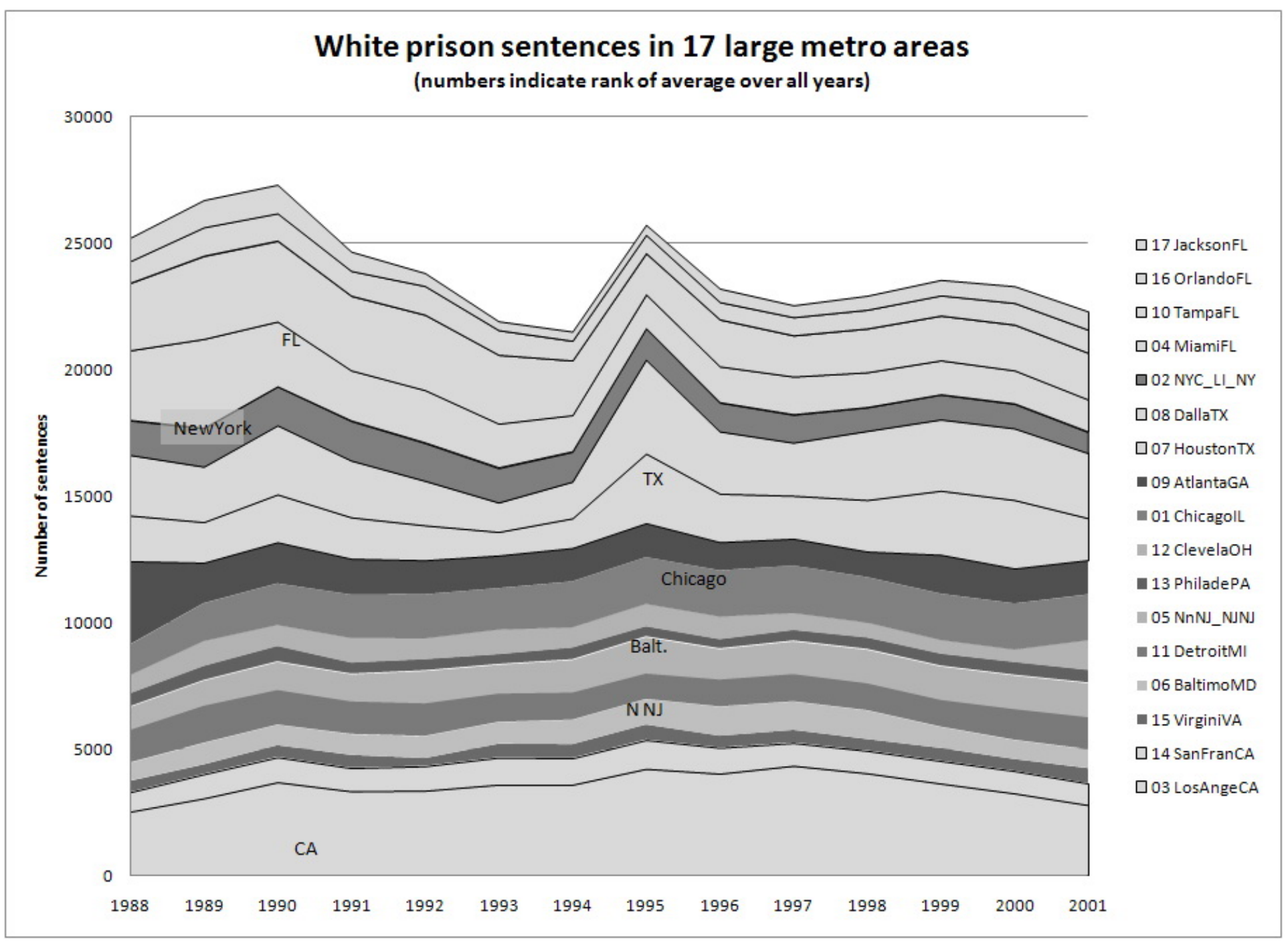

FIGURE 11. WHITE PRISON SENTENCES IN 17 LARGE METRO AREAS 1988-2001 


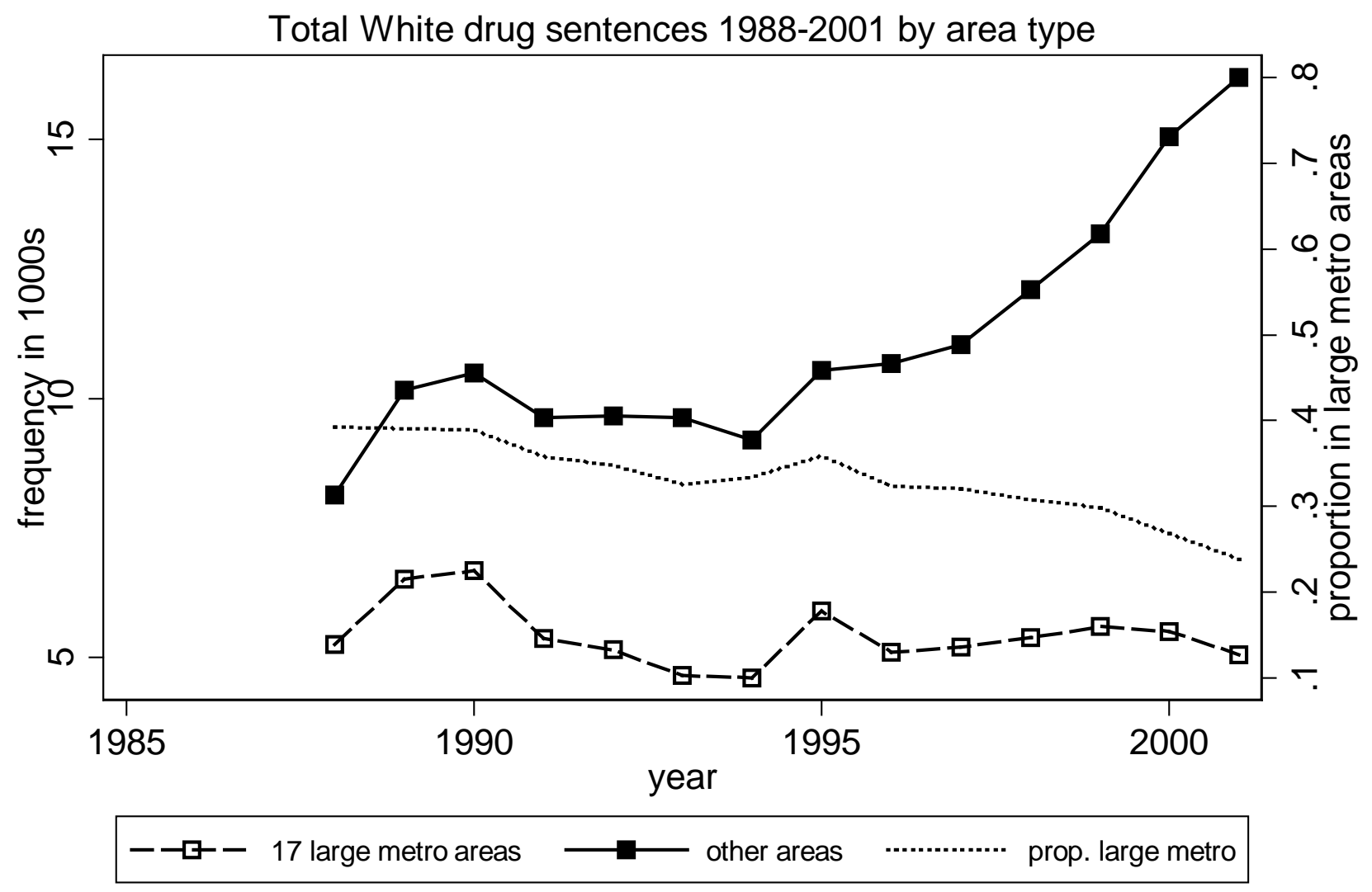

Areas with complete prison admission data only.

Large areas account for at least .01 of Black new sentences.

FIGURE 12. WHITE DRUG SENTENCES 1988-2001 BY AREA TYPE 


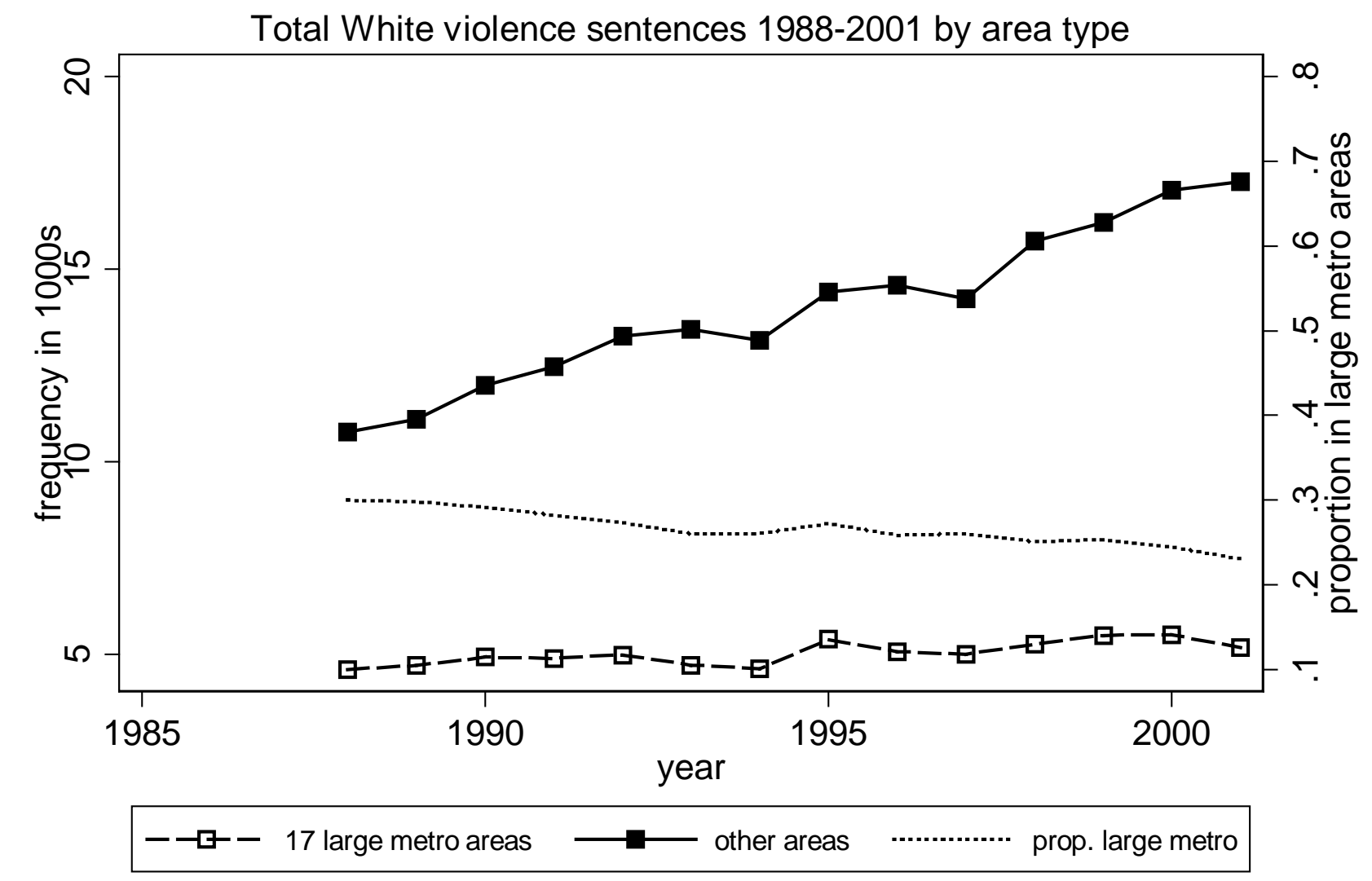

Areas with complete prison admission data only.

Large areas account for at least .01 of Black new sentences.

FIGURE 13. WHITE VIOLENCE SENTENCES 1988-2001 BY AREA TYPE 


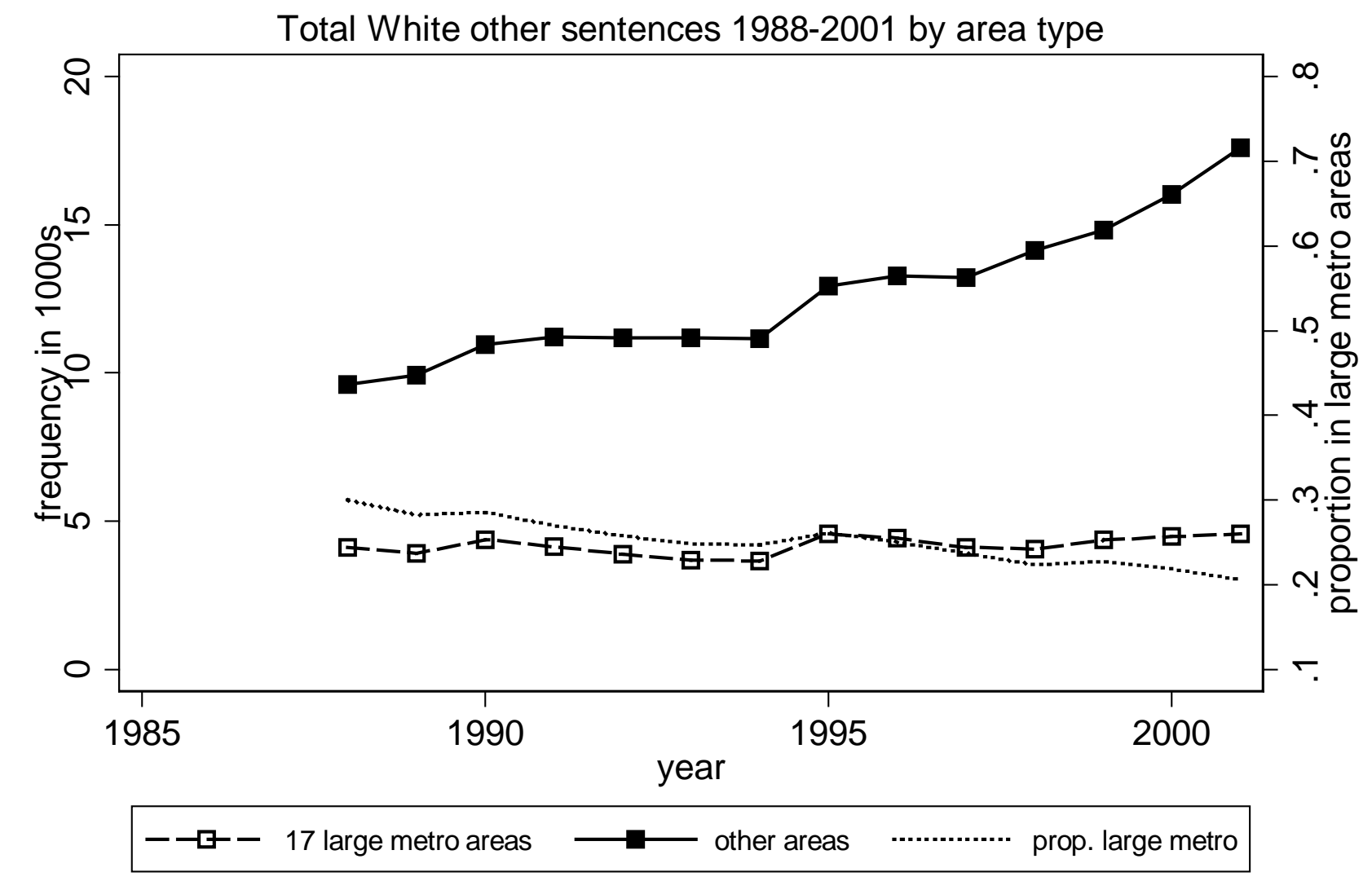

Areas with complete prison admission data only.

Large areas account for at least .01 of Black new sentences.

FIGURE 14. WHITE OTHER OFFENSE SENTENCES 1988-2001 BY AREA TYPE 


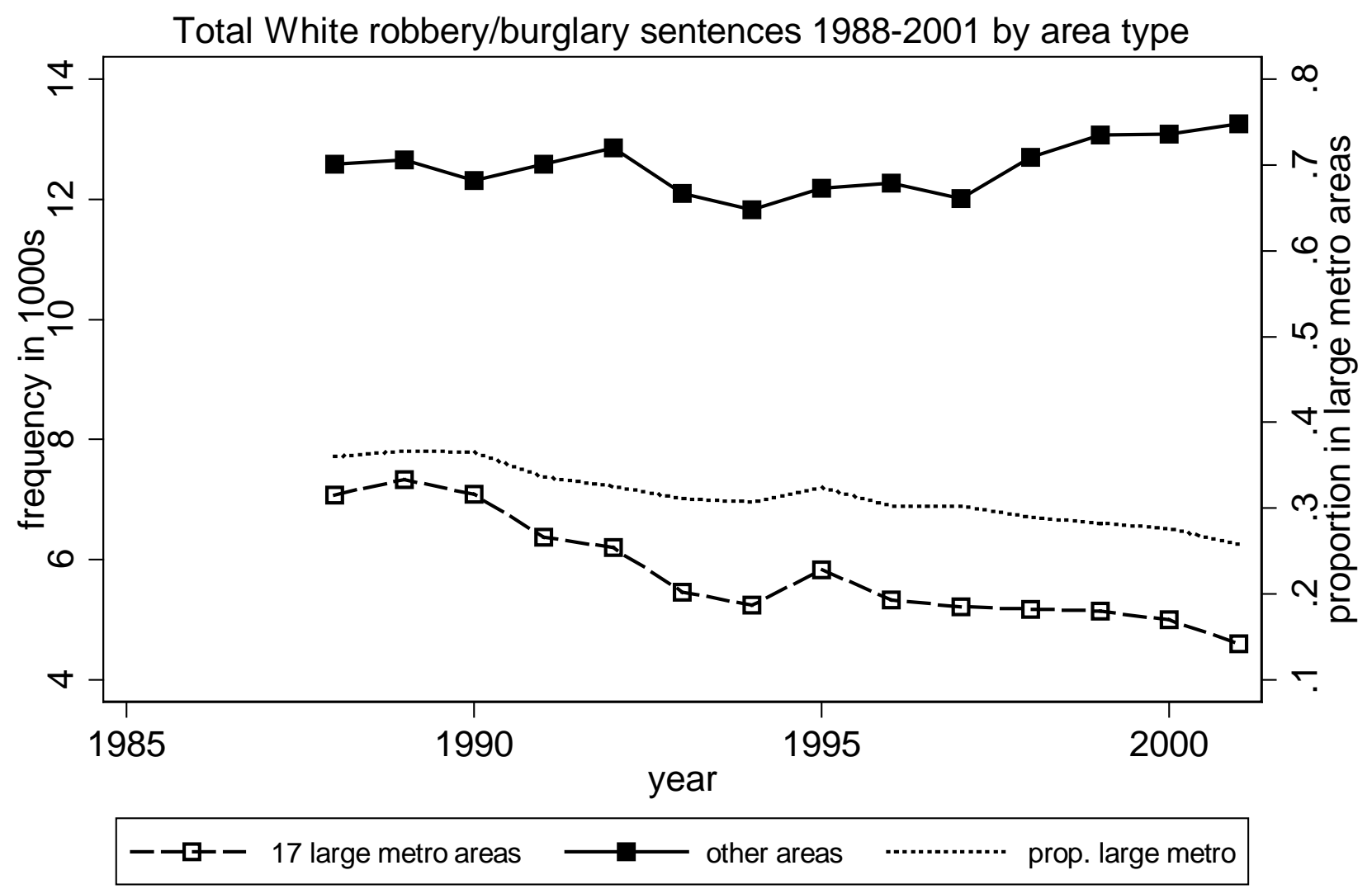

Areas with complete prison admission data only.

Large areas account for at least .01 of Black new sentences.

FIGURE 15. WHITE ROBBERY/BURGLARY SENTENCES 1988-2001 BY AREA TYPE 


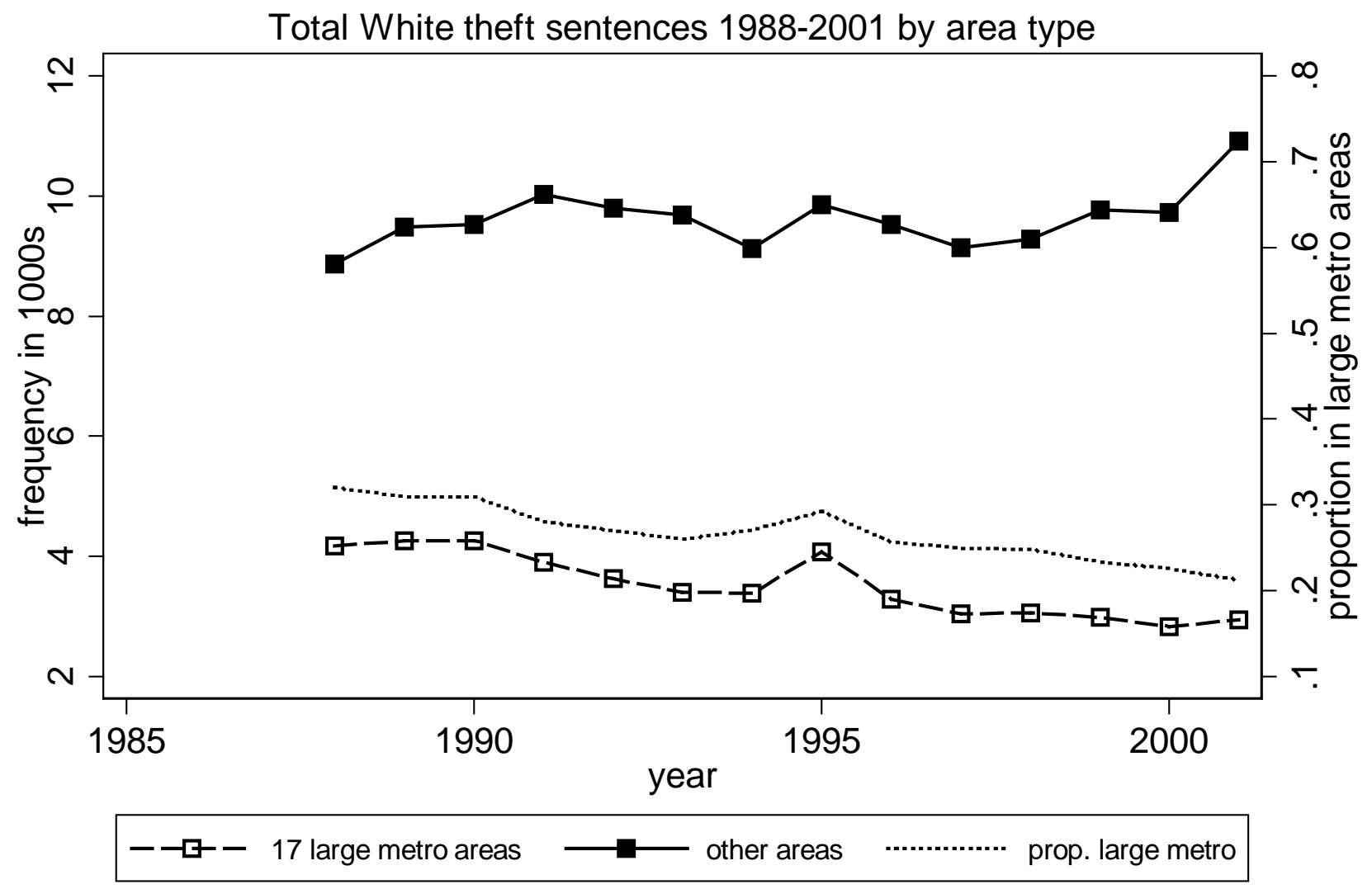

Areas with complete prison admission data only.

Large areas account for at least .01 of Black new sentences.

FIGURE 16. WHITE THEFT SENTENCES 1988-2001 BY AREA TYPE 


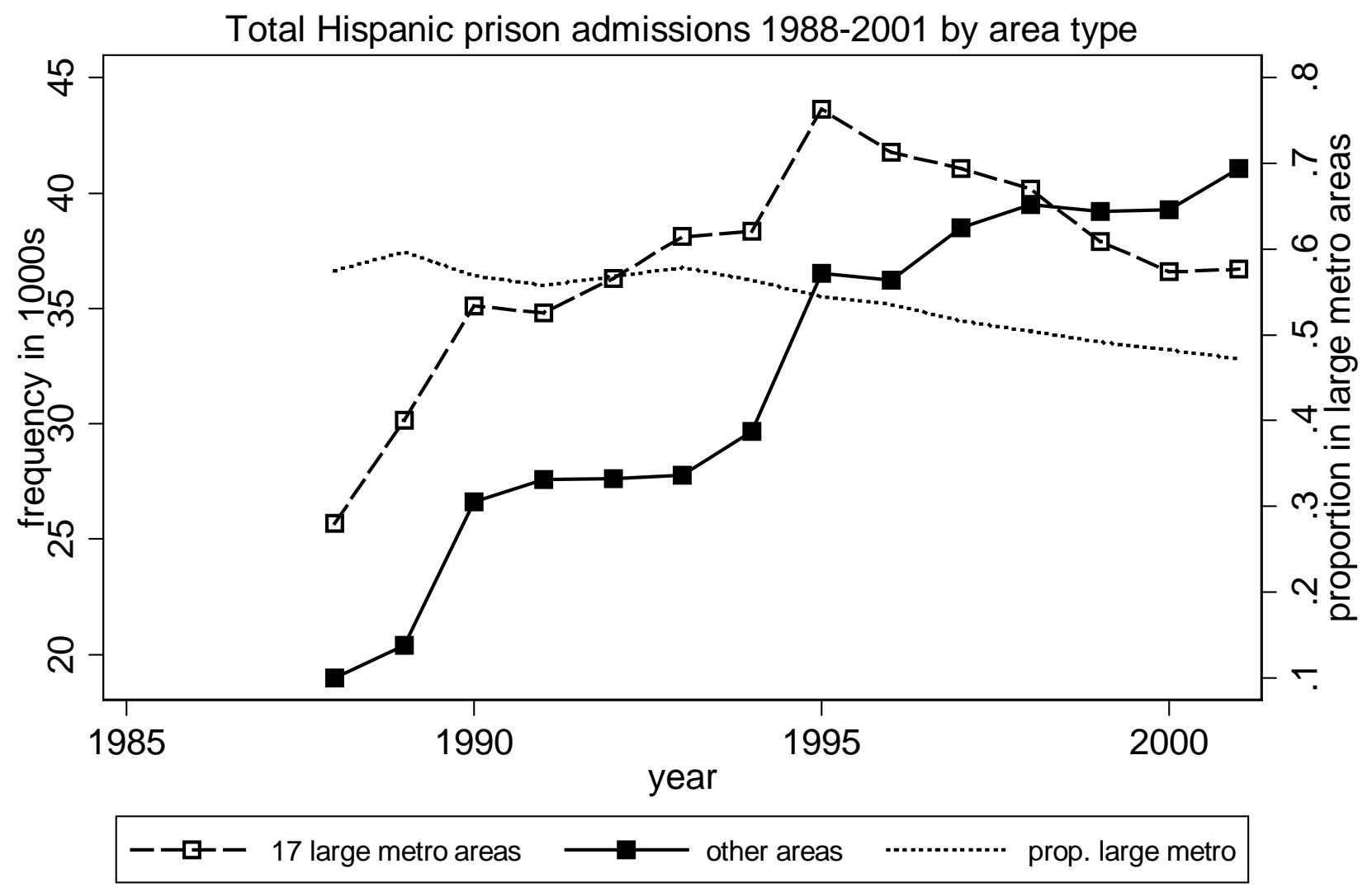

Areas with complete prison admission data only.

Large areas account for at least .01 of Black new sentences.

FIGURE 17. TOTAL HISPANIC PRISON ADMISSIONS 1988-2001 BY AREA TYPE 


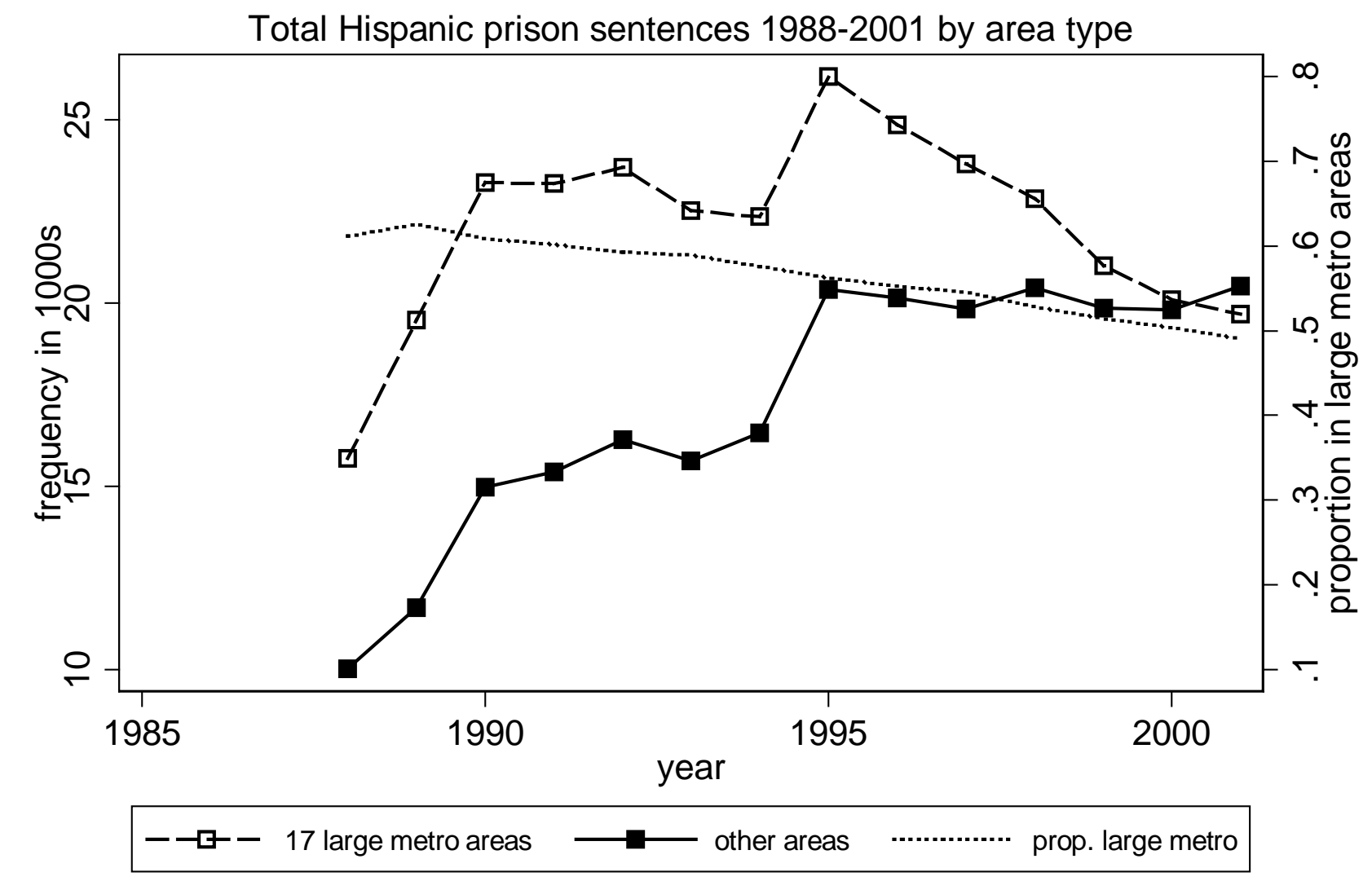

Areas with complete prison admission data only.

Large areas account for at least .01 of Black new sentences.

FIGURE 18. TOTAL HISPANIC PRISON SENTENCES 1988-2001 BY AREA TYPE 


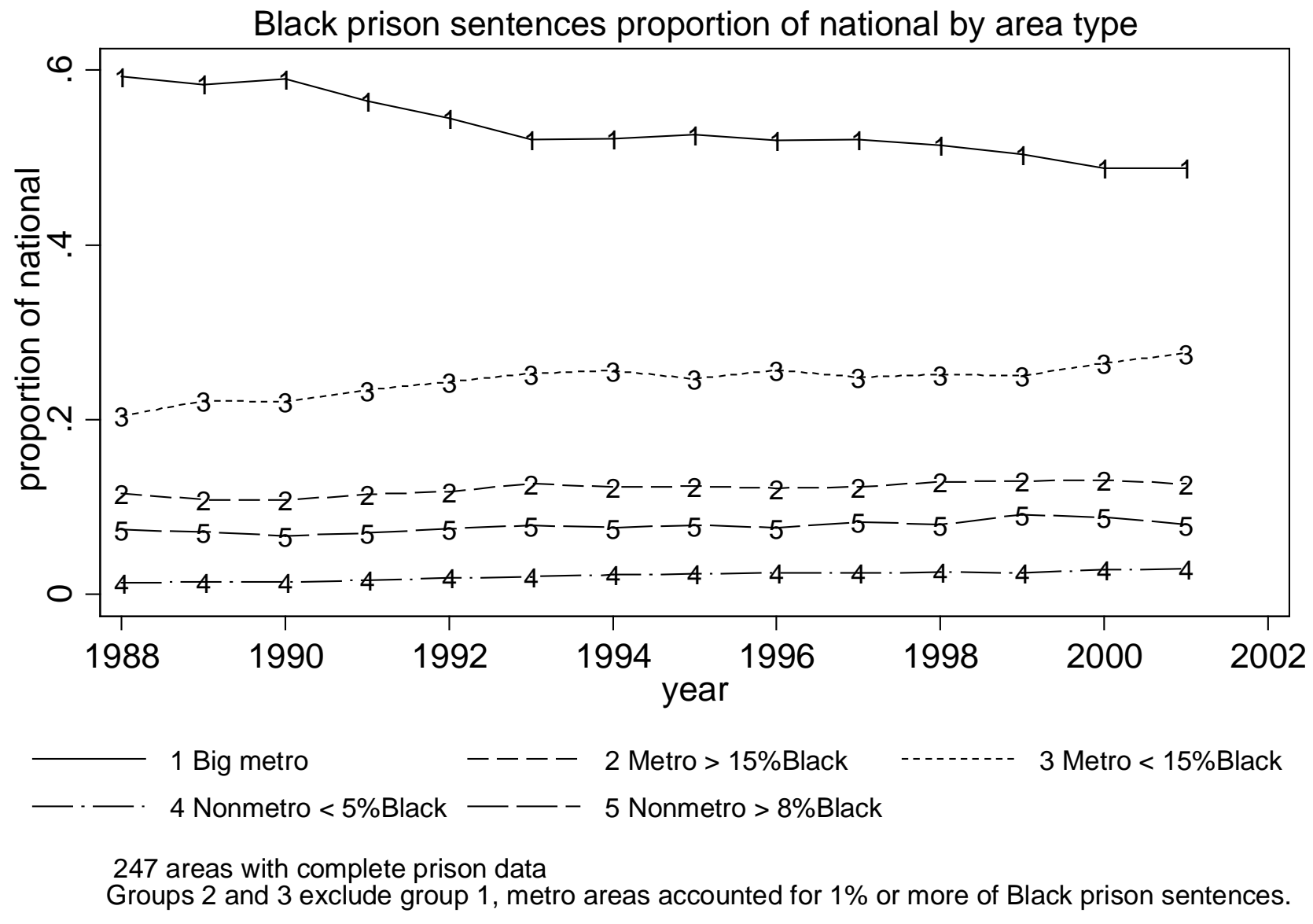

FIGURE 19. PROPORTION OF BLACK PRISON SENTENCES COMING FROM EACH AREA TYPE, 1988-2001 


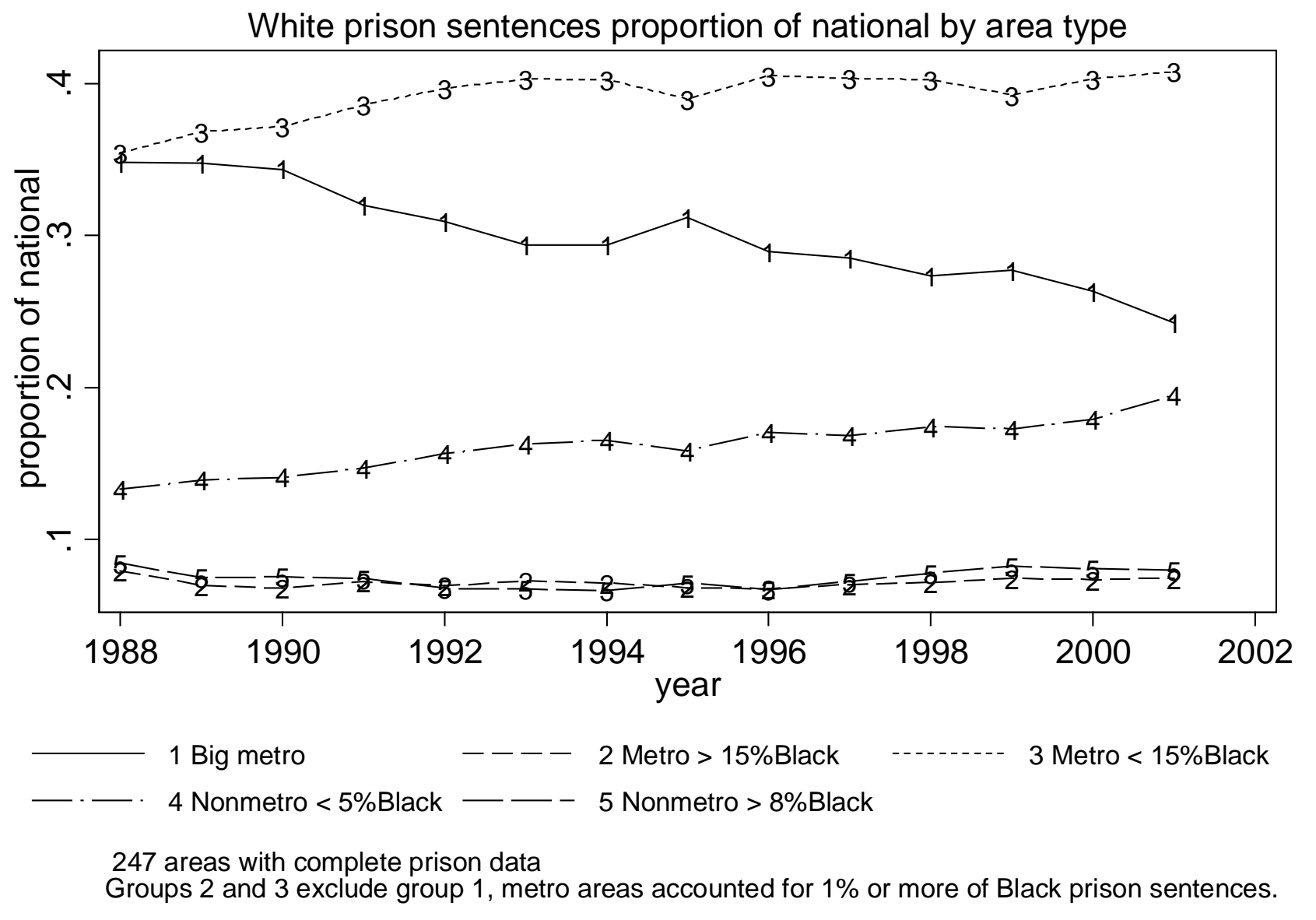

FIGURE 20. PROPORTION OF WHITE PRISON SENTENCES COMING FROM EACH AREA TYPE, 1988-2001 


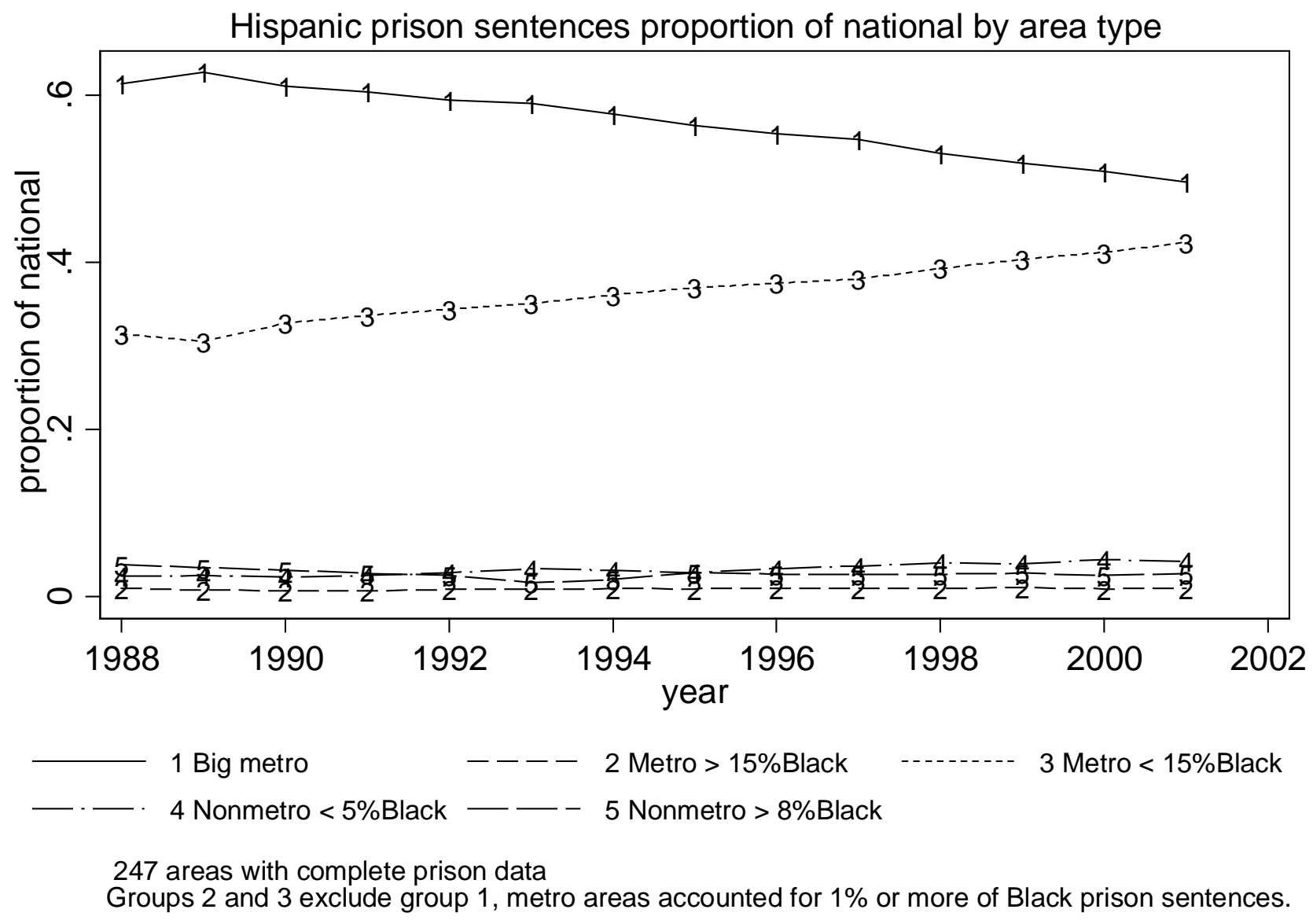

FIGURE 21. PROPORTION OF HISPANIC PRISON SENTENCES COMING FROM EACH AREA TYPE, 1988-2001 


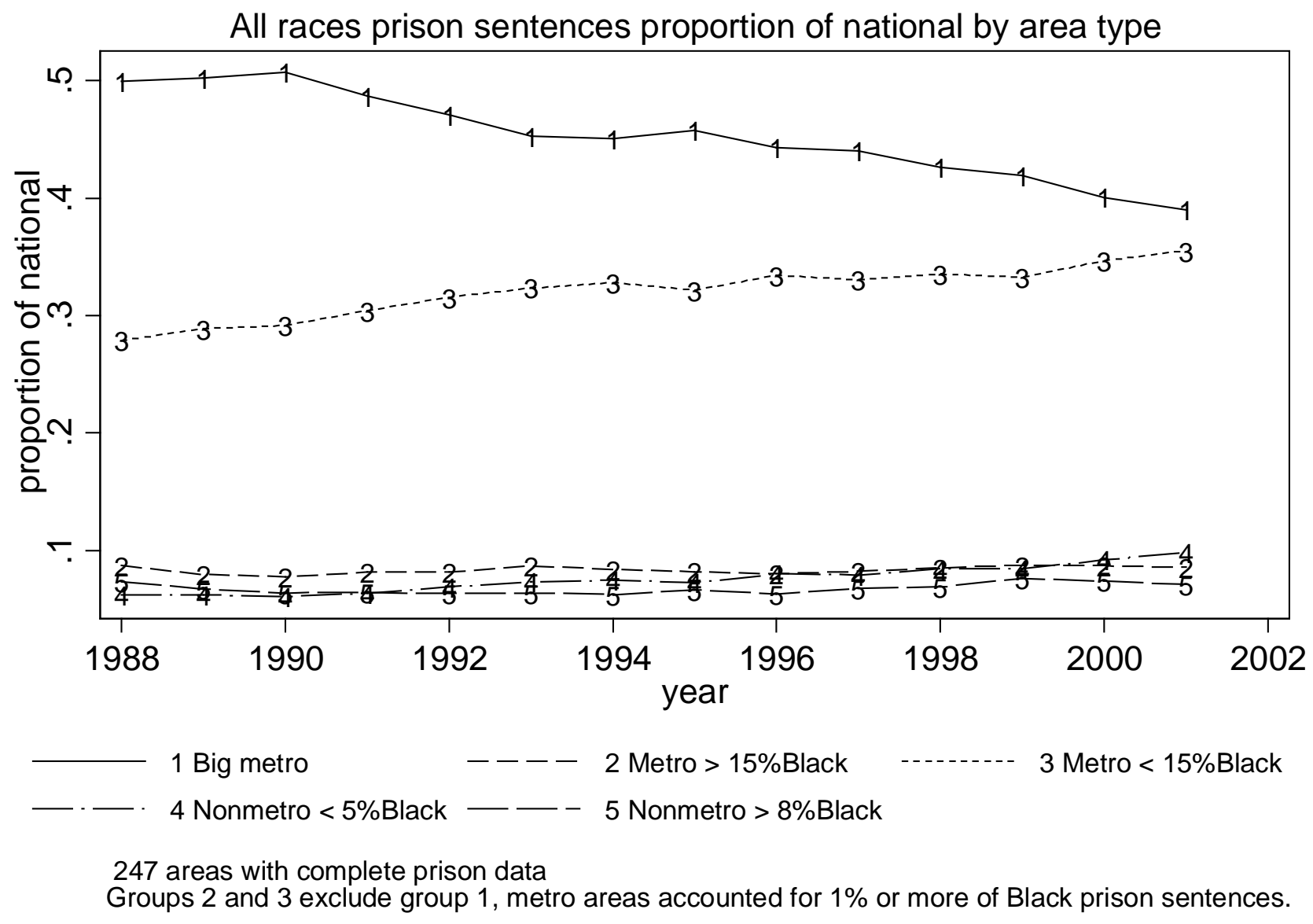

FIGURE 22. PROPORTION OF ALL PRISON SENTENCES COMING FROM EACH AREA TYPE, 1988-2001 


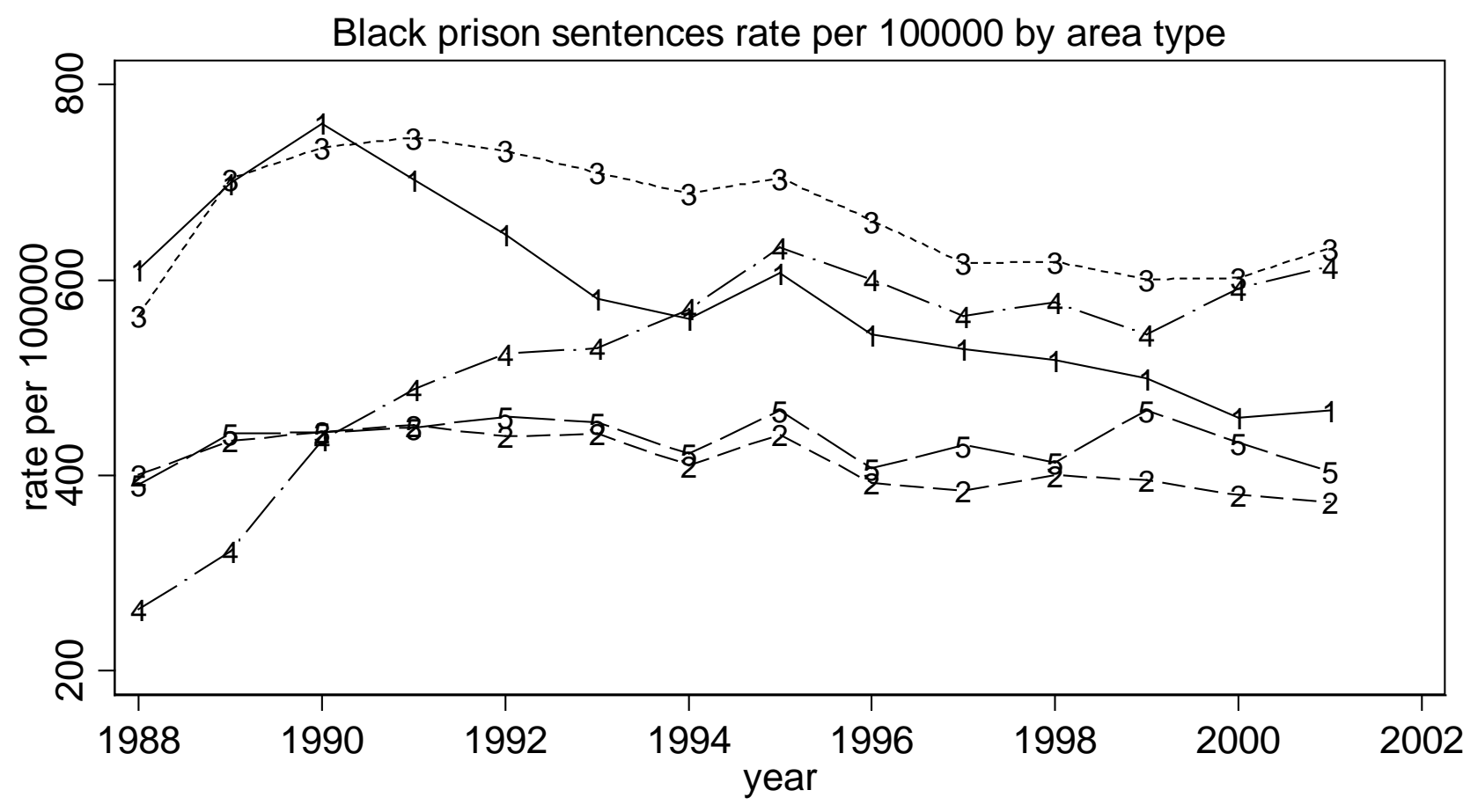

\section{Big metro $\quad----2$ Metro $>15 \%$ Black}

3 Metro $<15 \%$ Black

4 Nonmetro $<5 \%$ Black

\section{Nonmetro $>8 \%$ Black}

247 areas with complete prison data

Groups 2 and 3 exclude group 1, metro areas accounted for 1\% or more of Black prison sentences. 


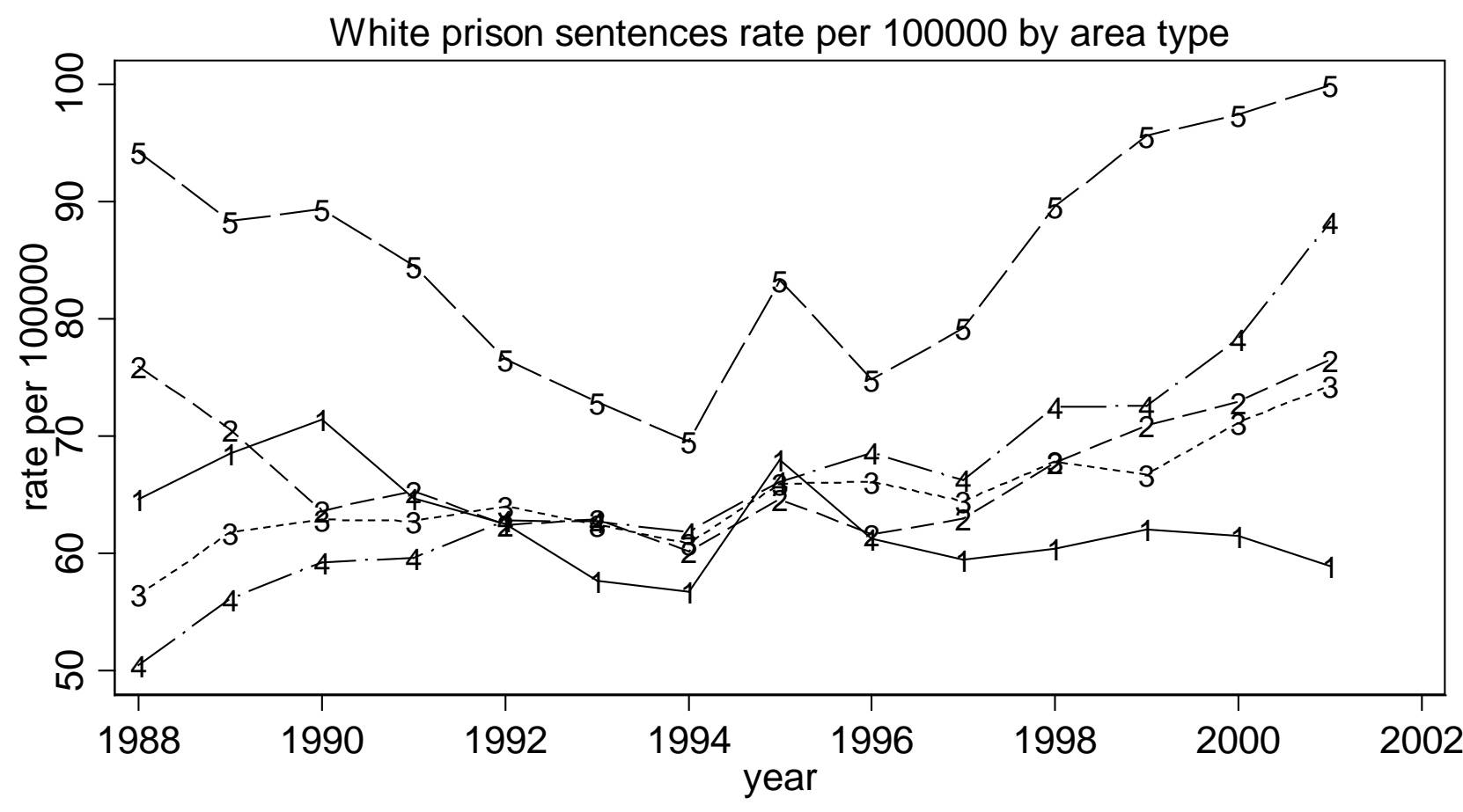

\section{Big metro $\quad-\quad---2$ Metro $>15 \%$ Black \\ - 4 Nonmetro $<5 \%$ Black \\ 5 Nonmetro > 8\%Black}

3 Metro $<15 \%$ Black

247 areas with complete prison data

Groups 2 and 3 exclude group 1, metro areas accounted for $1 \%$ or more of Black prison sentences.

FIGURE 24. WHITE PRISON SENTENCES RATE PER 100,000 BY AREA TYPE, 1988-2001 


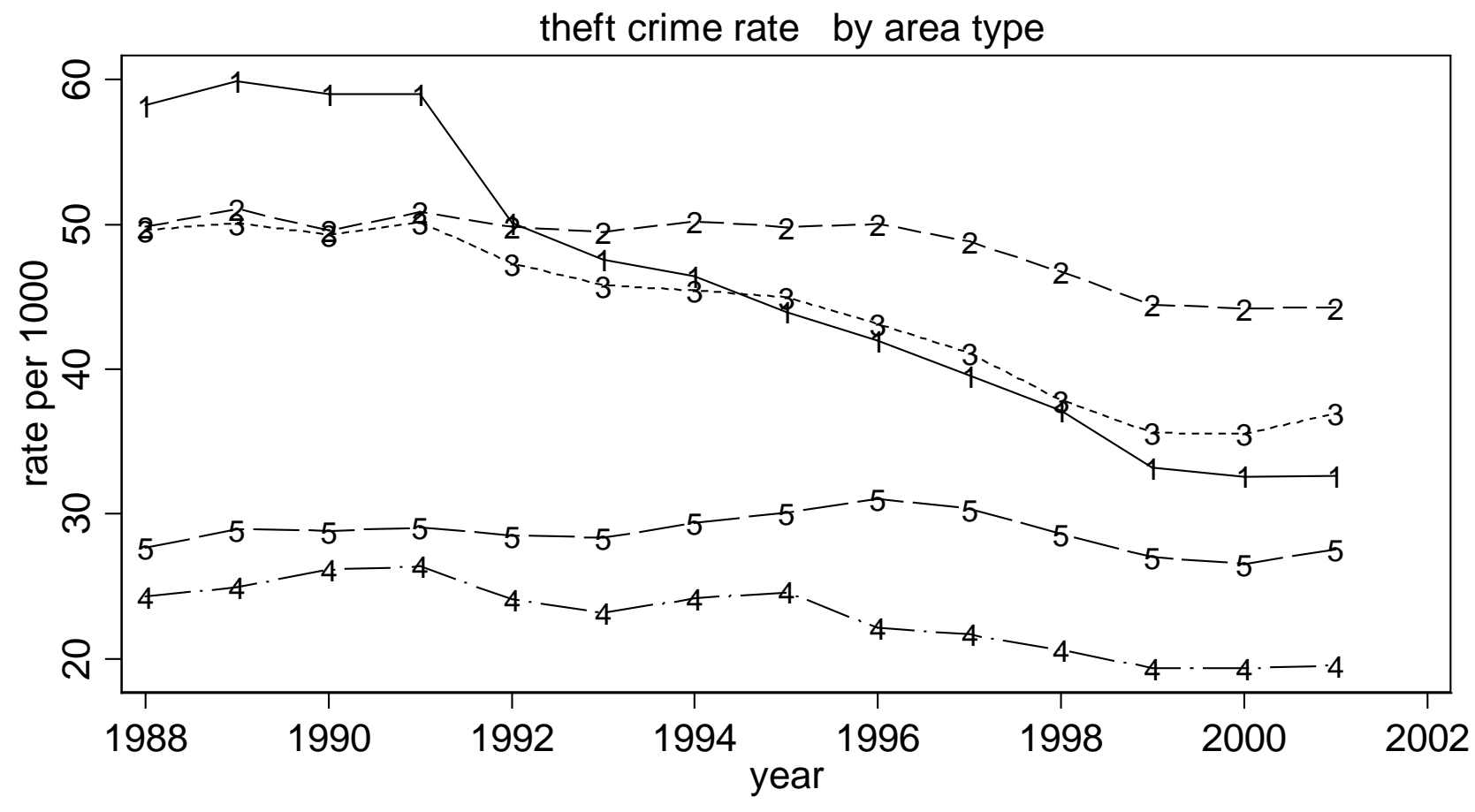

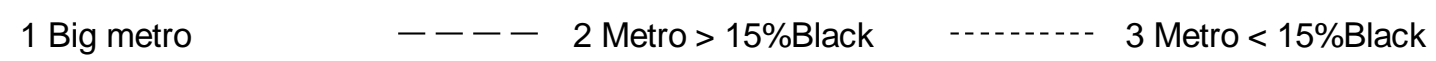

$$
4 \text { Nonmetro }<5 \% \text { Black — - } 5 \text { Nonmetro }>8 \% \text { Black }
$$

247 areas with complete prison data

Groups 2 and 3 exclude group 1, metro areas accounted for 1\% or more of Black prison sentences. 


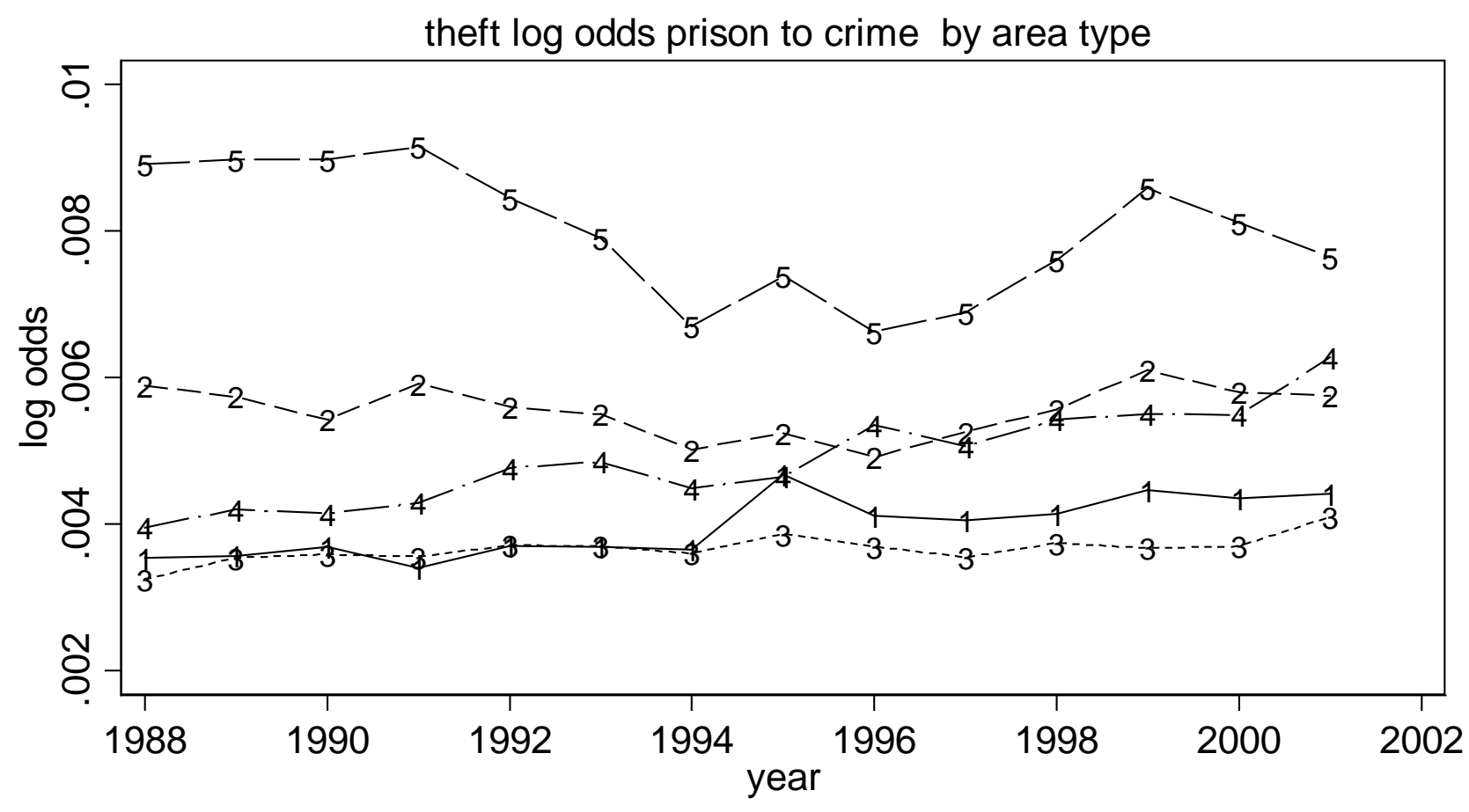

$$
1 \text { Big metro } \quad-1-2 \text { Metro }>15 \% \text { Black } \quad \text { - } \quad 2 \text { - } 3 \text { Metro }<15 \% \text { Black }
$$

—- - 4 Nonmetro < 5\%Black — — - 5 Nonmetro > 8\%Black

247 areas with complete prison data

Groups 2 and 3 exclude group 1, metro areas accounted for 1\% or more of Black prison sentences.

FIGURE 26. THEFT RATIO PRISON TO CRIME BY AREA TYPE, 1988-2001 


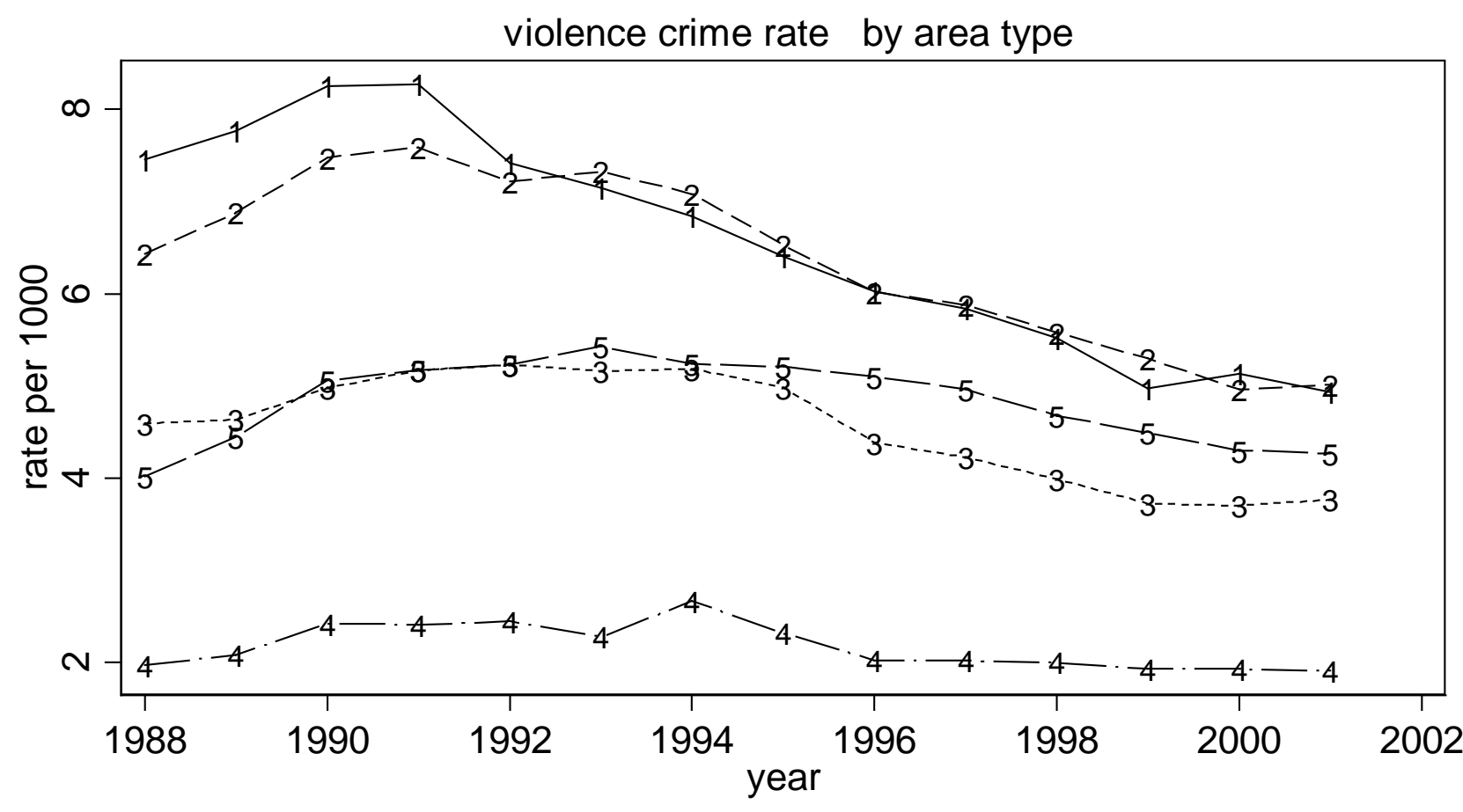

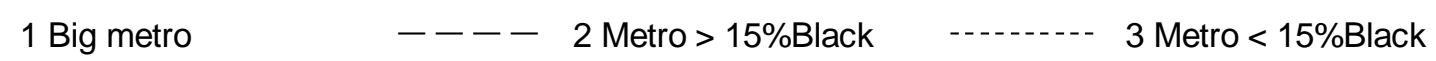

— - - 4 Nonmetro < 5\%Black — — - 5 Nonmetro > 8\%Black

247 areas with complete prison data

Groups 2 and 3 exclude group 1, metro areas accounted for 1\% or more of Black prison sentences. 


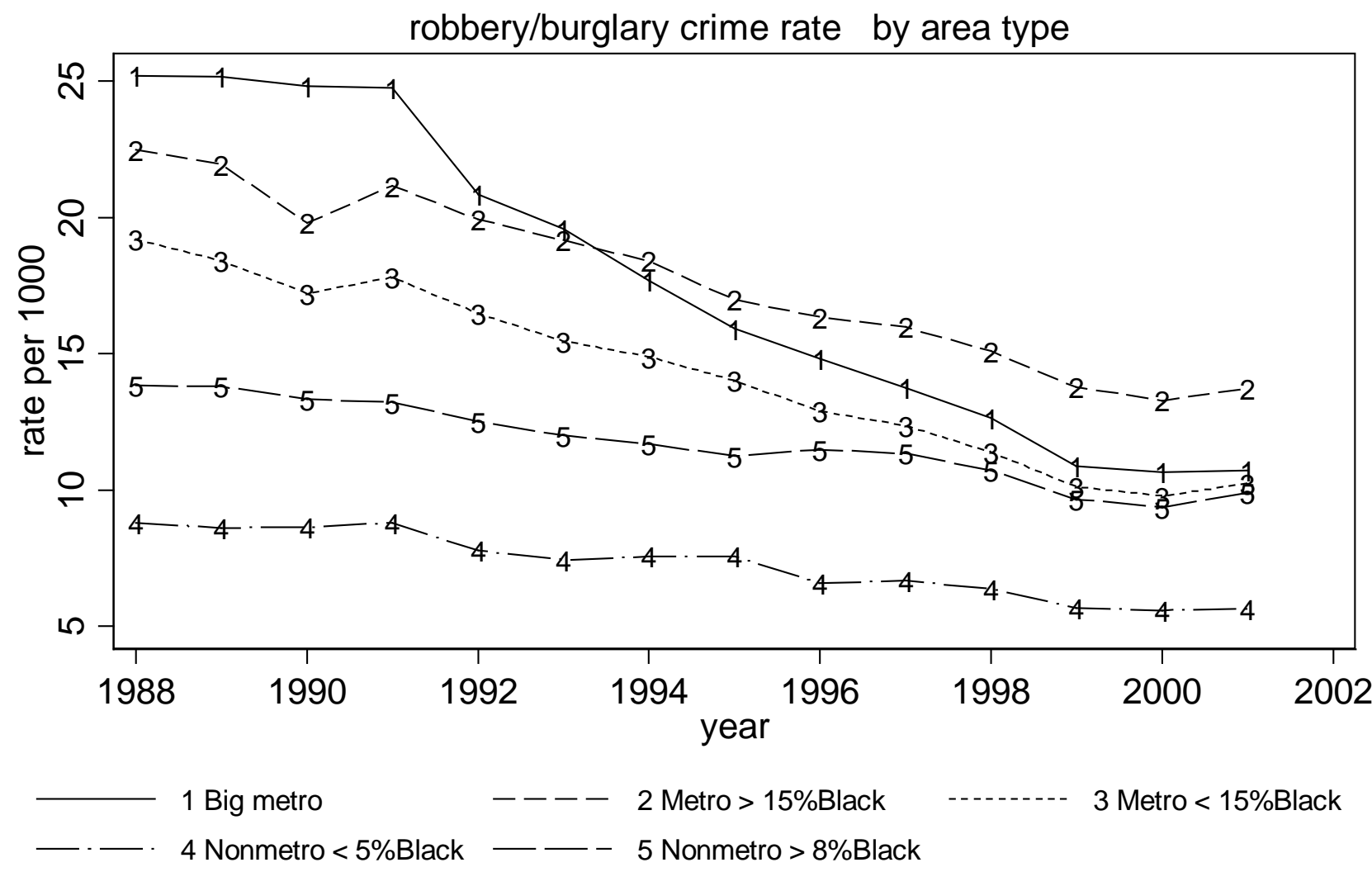

247 areas with complete prison data

Groups 2 and 3 exclude group 1, metro areas accounted for 1\% or more of Black prison sentences.

FIGURE 28. ROBBERY/BURGLARY CRIME RATE BY AREA TYPE, 1988-2001 


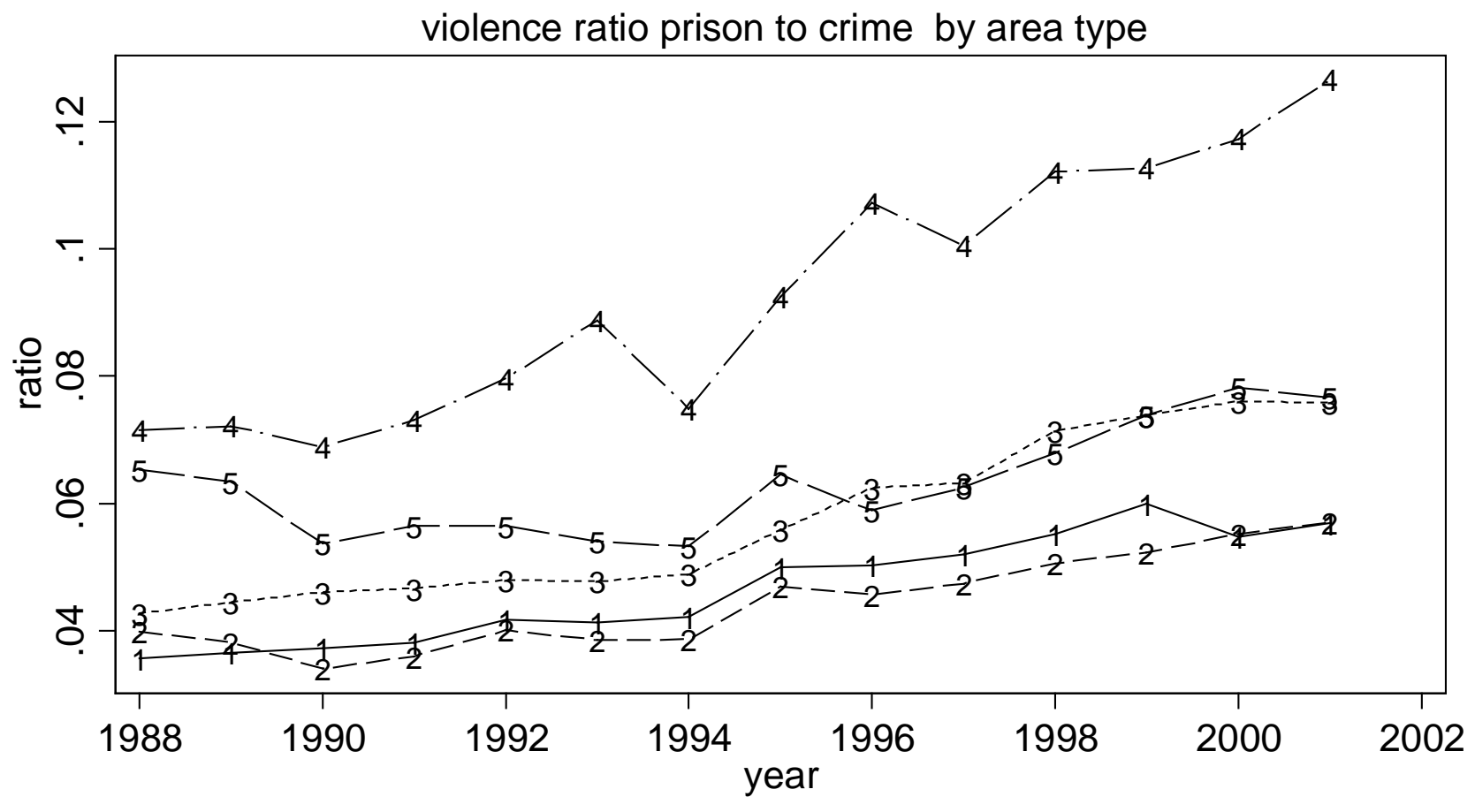

\footnotetext{
1 Big metro

----2 Metro > 15\%Black

3 Metro $<15 \%$ Black

—- - 4 Nonmetro < 5\%Black —— - 5 Nonmetro > 8\%Black
}

247 areas with complete prison data

Groups 2 and 3 exclude group 1, metro areas accounted for 1\% or more of Black prison sentences.

FIGURE 29. VIOLENCE RATIO PRISON TO CRIME BY AREA TYPE, 1988-2001 


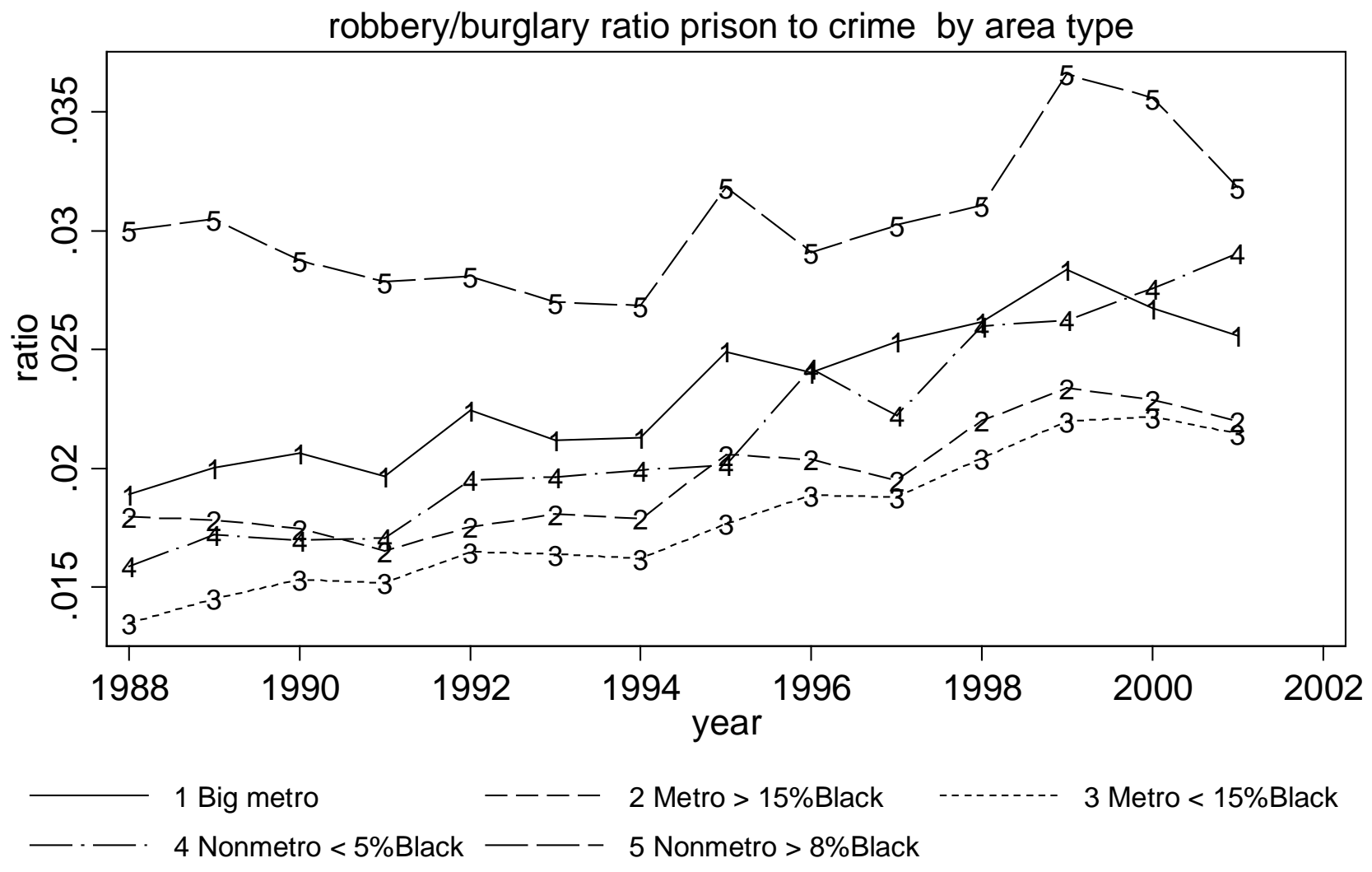

247 areas with complete prison data

Groups 2 and 3 exclude group 1, metro areas accounted for 1\% or more of Black prison sentences.

FIGURE 30. ROBBERY/BURGLARY RATIO PRISON TO CRIME BY AREA TYPE, 1988-2001 


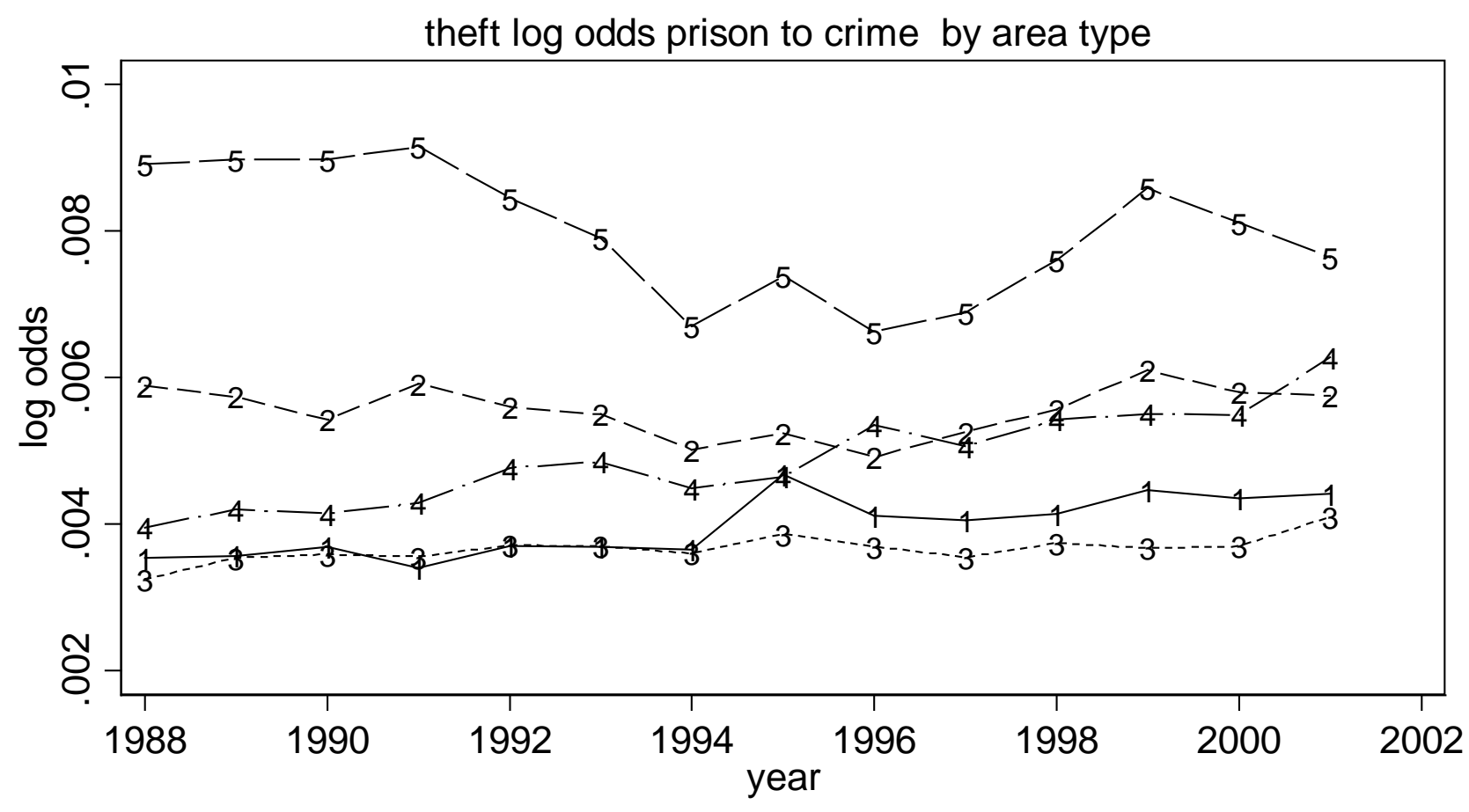

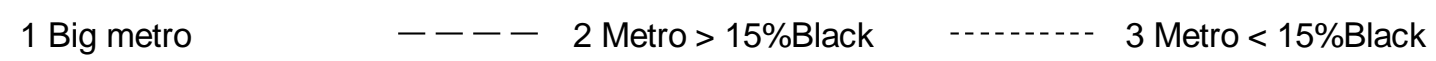

—- - 4 Nonmetro < 5\%Black — — - 5 Nonmetro > 8\%Black

247 areas with complete prison data

Groups 2 and 3 exclude group 1, metro areas accounted for 1\% or more of Black prison sentences.

FIGURE 31. THEFT LOG ODDS PRISON TO CRIME BY AREA TYPE, 1988-2001 


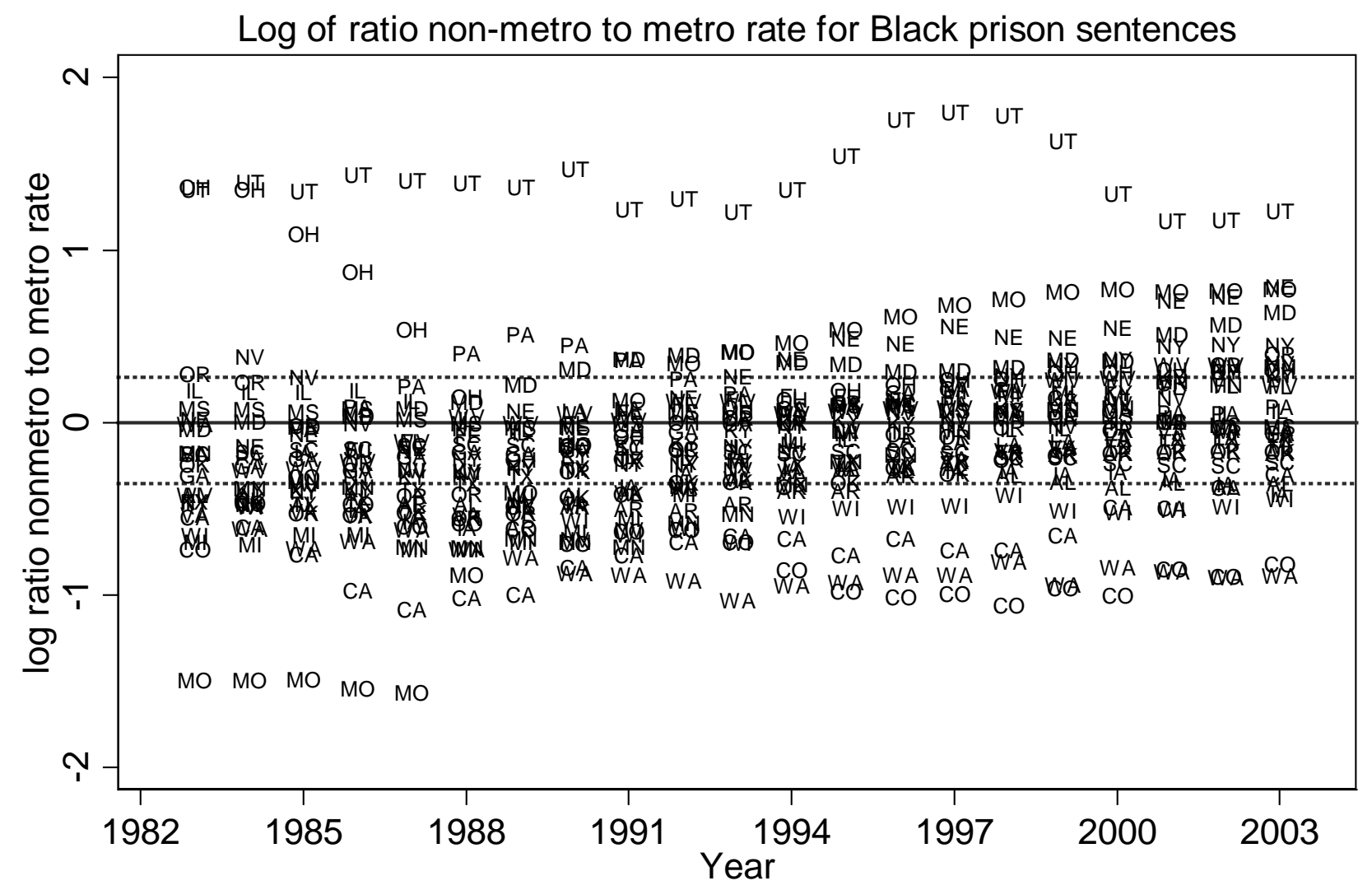

Ratios based on five-year moving average to reduce random variation.

Bands mark ratios between .7 and 1.3

FIGURE 32. LOG OF RATIO OF NON-METRO TO METRO RATE FOR BLACK PRISON SENTENCES, 1983-2003 


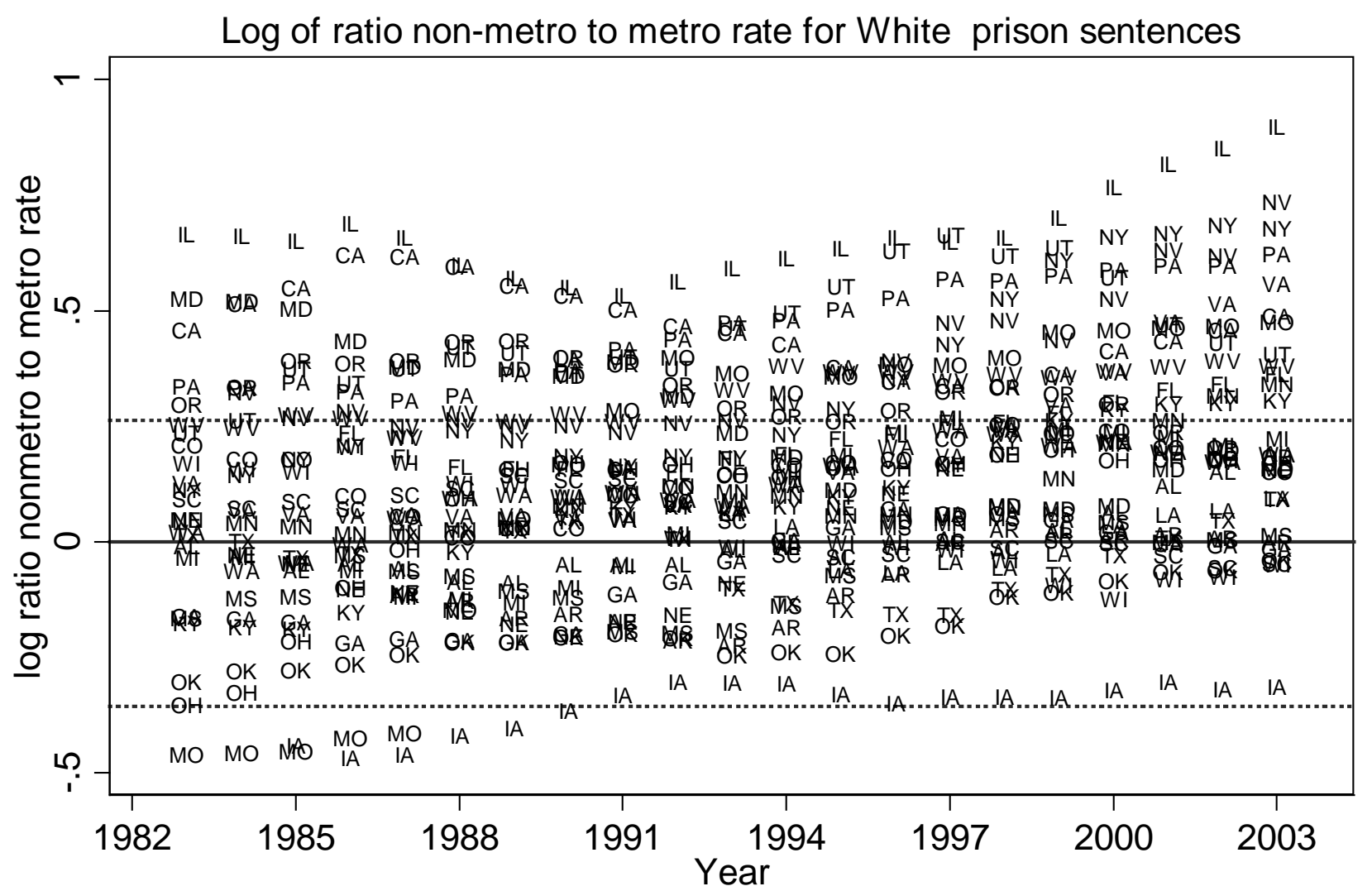

Ratios based on five-year moving average to reduce random variation.

Bands mark ratios between .7 and 1.3

FIGURE 33. LOG OF RATIO OF NON-METRO TO METRO RATE FOR WHITE PRISON SENTENCES, 1983-2003 
Notes

${ }^{1}$ These 17 were chosen because each one individually accounted for at least $1 \%$ of all Black prison sentences 19882001. If prison admissions rather than sentences were the criterion, we would include Riverside and San Diego counties in California and St. Louis MO and would swap out Virginia Beach.

${ }^{2}$ Add citation to Texas reentry study that explains this.

${ }^{3}$ Explain the Ohio problem.

${ }^{4}$ This threshold was chosen because the very high Black prison sentence rates occur below this threshold.

${ }^{5}$ This distribution is quite skewed. Alabama, Georgia, Mississippi and South Carolina were above $20 \%$, Virginia and Maryland at $13-14 \%$, Texas at $8 \%$. There were 8 states between $2 \%$ and $5.5 \%$ and seven states under $1.5 \%$.

${ }^{6}$ The figures supporting these paragraphs are not included but are supplied in an on-line appendix for reference.

${ }^{7}$ This is the first thing that every person I have discussed these results with has mentioned. "What about meth?" is the usual way the question is asked.

${ }^{8}$ My state, Wisconsin, is one of the exceptions where metro-area Whites still had higher imprisonment rates than non-metro Whites in 2002. 